\title{
PROPUESTAS DE REFORMA A LOS PARTIDOS POLÍTICOS EN CHILE*
}

\author{
Francisco Javier Díaz \\ Cieplan \\ Lucas Sierra \\ CEP
}

\begin{abstract}
A continuación se reproduce la segunda parte del libro Democracia con Partidos (2012), que contiene los resultados del proyecto de investigación que conjuntamente realizaron el CEP y CIEPLAN. Esta sintetiza las conclusiones de esa investigación y avanza un conjunto de propuestas para mejorar la calidad institucional de la política en Chile.

En forma paralela a una acuciosa revisión del tratamiento que dieron las Constituciones chilenas a los partidos políticos $(1828,1833,1925,1980)$, y al conjunto de leyes que en la historia de Chile se ocuparon de los partidos, se proponen varias modificaciones a la legislación de los partidos políticos
\end{abstract}

Francisco Javier Díaz. Abogado, Universidad de Chile; MS en Ciencia Política, London School of Economics. Investigador senior en la Corporación de Estudios para Latinoamérica (CIEPLAN). Dirección electrónica: jorge. pacheco@cieplan.org.

Lucas Sierra. Abogado, Universidad de Chile; Ll.M., Universidad de Yale. Coordinador Académico del Centro de Estudios Públicos. Dirección electrónica:1sierra@cepchile.cl.

* Segunda parte del libro Democracia con Partidos (Santiago: CEP/ CIEPLAN, octubre 2012), editado por Francisco Javier Díaz y Lucas Sierra. 
con una mirada sistémica, que tenga en cuenta el contexto institucional completo en que éstos operan. Esta reforma pasa por un perfeccionamiento de la Constitución y las leyes que regulan a los partidos políticos. Las propuestas de modificación se refieren a la conformación del Congreso, el tipo de sistema electoral, el mapa de los distritos y circunscripciones, como también a los mecanismos para reemplazar a parlamentarios renunciantes, el lobby, la declaración patrimonial y los conflictos de intereses. A su vez, la propuesta se detiene en la ley de 2003 que regula y fiscaliza los aportes privados a la política, materia sobre la cual los autores de este documento discrepan entre sí en algunos aspectos, por lo que cada uno expone su posición por separado.

Contenido:

2.1. Antecedentes constitucionales y legislativos de la Ley 18.603, orgánica constitucional de partidos políticos 217

2.2. Propuestas de reformas institucionales en torno a la LOC de partidos políticos 236

2.3. Reformas específicas a la LOC de partidos políticos

\subsection{ANTECEDENTES CONSTITUCIONALES Y LEGISLATIVOS DE LA LEY 18.603, ORGÁNICA CONSTITUCIONAL DE PARTIDOS POLÍTICOS (LOC DE PARTIDOS POLÍTICOS)}

$\mathrm{H}$ asta que se dictó la vigente Ley 18.603 en 1987 — esto es, la LOC de Partidos Políticos-, la tradición jurídica chilena fue, como ha escrito Enrique Barros ${ }^{1}$, "francamente reticente en materia de regulación legal de los partidos políticos" (1984: 174). Antes de esa fecha, esta regulación legal fue escasa.

Por lo pronto, nunca hasta 1987 hubo una "ley de partidos" como tal. Durante el siglo XIX ni la Constitución ni la ley se refirieron a los partidos. Las Constituciones se refirieron a la política, pero no a los partidos. A continuación, las constituciones, empezando por la Constitución de 1828.

${ }^{1}$ Enrique Barros (1984), “Aspectos jurídicos del estatuto de los partidos políticos". Estudios Públicos 14: 171-217. Disponible en http://www. cepchile.cl/dms/lang_1/doc_1306.html 


\subsubsection{Constitución de 1828}

Así se refiere a la política su mensaje:

...Constitución chilena, que de ahora en adelante debemos mirar como el principal elemento de nuestra existencia política,

...el Poder Supremo de la Nación, el que reúne en sí la plenitud de la soberanía, está tan lejos de la nulidad a que lo condenan en otras partes las aspiraciones del gobierno, como de la omnipotencia parlamentaria, que rompiendo el equilibrio de las fuerzas políticas ha sido siempre el azote de los pueblos.

... los Congresos futuros nos darán sin duda códigos análogos a las instituciones políticas de nuestro país.

Y ordenaba su Art. 1: "La Nación chilena es la reunión política de todos los chilenos naturales y legales."

Varias referencias a la política, como se ve, pero ninguna a los partidos políticos.

\subsubsection{Constitución de 1833}

Esta Constitución escasamente se refirió a la política, ni qué hablar de los partidos políticos. Solo dijo "política" una vez y a propósito de las relaciones exteriores del país:

Artículo 82. Son atribuciones especiales del Presidente:

$19^{\circ}$. Mantener las relaciones políticas con las naciones extranjeras, recibir sus Ministros, admitir sus cónsules, conducir las negociaciones, hacer las estipulaciones preliminares, concluir y firmar todos los tratados de paz, de alianza, de tregua, de neutralidad, de comercio, concordatos y otras convenciones.

\subsubsection{Ley 2.883 de 1914}

Las leyes se refirieron a los partidos políticos antes que las constituciones. La primera ley que los nombra es la Ley 2.883 de febrero de 
1914, "Lei de Elecciones", que fue reformada por la Ley 2.893 de junio del mismo año ${ }^{2}$.

Estas fueron las disposiciones de la Ley 2.883 que se refirieron a los partidos, todo a propósito, por supuesto, del proceso electoral:

Art. 20. Las juntas inscriptoras permanecerán reunidas desde la una hasta las cuatro de la tarde durante veinte dias consecutivos en las comunas o circunscripciones que tengan hasta quince mil habitantes; durante veinticinco dias en las que tengan hasta treinta mil habitantes, i durante treinta dias en las que tengan mas de este número.

Las juntas que se instalen con posterioridad al dia señalado en el artículo anterior, completarán el número de dias que deben funcionar segun lo determinado por la lei.

La junta inscriptora, diariamente, al suspenderse los trabajos, pondrá, a continuacion de la última inscripcion, una nota en que espresará en letras el número de los individuos inscritos en el dia, firmada por todos los vocales i apoderados de los partidos, quienes rubricarán las hojas del rejistro en que se hubieren hecho las inscripciones. Remitirá tambien, diariamente, al Juzgado de turno en lo civil una lista de los ciudadanos inscritos con indicacion del nombre, profesion i residencia de éstos, firmada por los miembros de la junta i apoderados de los partidos. Una copia autorizada de esta lista será publicada en un diario o periódico de la cabecera del departamento, o en su defecto en uno de la cabecera de la provincia. Esta lista se hará por secciones i por órden numérico de inscripcion.

Durante la suspension del trabajo, el comisario guardará los rejistros bajo su responsabilidad.

Art. 35. La junta hará las inscripciones i esclusiones que ocurran procediendo de la manera siguiente:

El tercer domingo de Abril, a las dos de la tarde, se reunirán en la sala municipal de la comuna los miembros de la junta inscriptora i procederán a constituirse, nombrando un presidente i un secretario. La votacion se hará por voto uninominal, quedando elejido presidente el que obtenga mayor número de votos i secretario el segundo. En caso de empate decidirá la suerte. Designará tambien. por mayoria de votos, un comisario.

${ }^{2}$ La Ley 2.883 está disponible en: http://www.leychile.cl/Navegar?idN orma $=23565 \&$ buscar=ley+2883. La Ley 2.893 está disponible en: http://www. leychile.cl/Navegar?idNorma $=23573 \&$ buscar $=$ partidos +1914 
La junta no podrá constituirse sin la mayoria absoluta del número de vocales que la forman. Si no pudiere constituirse por falta de número, los asistentes darán aviso por escrito al Gobernador del departamento i al juez del crímen de turno. Este hará citar a los inasistentes i a los suplentes para que concurran al lugar designado, dentro de tercero dia, a las doce del dia, a fin de constituir la junta, sin perjuicio de seguir el respectivo proceso. Los suplentes entrarán a reemplazar a los propietarios inasistentes por órden alfabético de apellido, $\mathrm{i}$, en caso de igualdad de apellidos, por órden alfabético de nombres.

Desde el $1 .^{\circ}$ hasta el 10 de Mayo i desde el $1 .^{\circ}$ hasta el 10 de Noviembre de cada año, las juntas inscriptoras harán las inscripciones que se soliciten.

Las juntas funcionarán en los dias indicados desde la una hasta las cuatro de la tarde i diariamente levantarán, en una de las hojas del rejistro destinado a este objeto, acta de todo lo obrado, que firmarán todos sus miembros presentes.

Tambien diariamente, al suspenderse los trabajos, pondrán a continuacion de la última inscripcion una nota en que espresarán en letras i cifras el número de los individuos inscritos en el dia, firmada por todos los vocales y vocales adjuntos o apoderados de los partidos, quienes rubricarán, ademas, las hojas del rejistro en que se hubieren hecho las inscripciones. Al mismo tiempo una lista con el nombre i apellidos, residencia i profesion $\mathrm{u}$ oficio de los ciudadanos inscritos, firmada por todos los miembros de la junta i apoderados de los partidos será remitida diariamente al Juzgado i a un diario o periódico de la cabecera del departamento, o a falta de éste a uno de la cabecera de la provincia para su publicacion, dejándose testimonio de la entrega de esta lista al secretario del Juzgado en recibos firmados por éste que se protocolizarán en la Notaria mas antigua del departamento. Igual lista se fijará en la oficina del conservador de bienes raíces i en la sala municipal.

Art. 104. Cada uno de los partidos políticos existentes en la República, con representacion en el Congreso, tendrá derecho a designar un vocal adjunto, con voz pero sin voto, que asista al funcionamiento de cada junta o comision electoral, como miembro nato de ella, pudiendo incorporarse en cualquier momento, i sirviéndole de titulo suficiente el nombramiento que le otorgue el directorio que tenga el partido en el departamento, autorizado por un notario. 
Cada uno de los candidatos a cualquiera de los cargos por que se vote en la eleccion, tiene derecho para hacerse representar en todos los actos electorales por un apoderado, cuya representacion se hará constar por escrito, autorizando la firma gratuitamente un notario de la provincia.

Los apoderados de los candidatos tienen derecho para sentarse al lado de los funcionarios que intervengan en el acto electoral que se trata de vijilar, ya sea que las juntas, comisiones o colejios electorales practiquen inscripciones o reciban la votacion o hagan escrutinios parciales o jenerales.

La colocacion de esos apoderados será la que indica el diseño que se acompaña a esta lei. Tienen derecho para observar los procedimientos de las juntas, comisiones o colejios, para objetar la identidad del elector i examinar la firma de los sufragantes, $i$ en jeneral para todo lo que conduzca al desempeño de su mandato.

La junta, comision o colejio deberá hacer constar, en el acta de sus procedimientos los hechos cuya anotacion pida cualquiera de ellos, i no podrá denegar el testimonio por motivo alguno.

Los apoderados deberán poner en la antefirma una protesta de los hechos que la junta, comision o colejio se negare a consignar.

La parte del acta relativa a la instalacion de la comision receptora se inscribirá en el rejistro ántes de principiar la recepcion de los sufrajios i se hará constar la concurrencia de los apoderados.

Pocos meses más tarde, la Ley 2.983 modificó a la anterior, refiriéndose a los partidos en una nueva disposición:

f) Se intercalan a continuacion del inciso $3 .^{\circ}$ del artículo 26 los siguientes incisos:

Para los efectos de la inscripcion en los rejistros electorales se reputará, en caso de duda, como residente en la subdelegacion, al propietario del predio rústico o urbano situado en ella o al que justifique haber vivido dentro de sus límites, tres meses ántes de la inscripcion por lo ménos.

Se entenderá que hai duda sobre la residencia, siempre que la objete ante la Junta Inscriptora cualquier apoderado de los partidos o candidatos. 


\subsubsection{Constitución de 1925}

Esta Constitución volvió a hablar de la política y, por primera vez a nivel de una regla constitucional, se refirió a los "partidos políticos". Decía su Art. 25:

Artículo 25. En las elecciones de Diputados y Senadores se empleará un procedimiento que dé por resultado en la práctica una efectiva proporcionalidad en la representación de las opiniones y de los partidos políticos.

Es una alusión importante: no solo les reconoce su papel en el funcionamiento de la institucionalidad política, sino que, además, les asegura una efectiva proporcionalidad en el ejercicio de ese papel.

Pero no iba a ser sino hasta 1971, con la entrada en vigencia del llamado "Estatuto de Garantías Constitucionales", que los partidos políticos alcanzaron el nivel de regulación constitucional que exhiben hoy. Pero antes de eso, revisemos brevemente la Ley 14.852 de 1962, Ley General de Elecciones.

\subsubsection{Ley 14.852, Ley General de Elecciones de 1962}

Tal como la Ley 2.883 de 1914 que se mencionó más arriba, esta ley también reguló a los partidos a propósito de los procesos eleccionarios. Pero, a diferencia de la Ley 2.883 de 1914, esta Ley 14.852 también reguló aspectos más bien orgánicos de los partidos, no puramente electorales ${ }^{3}$.

El Art. 20 de la Ley 14.852 fue clave a este respecto. Reguló su constitución y el momento en el cual adquirían personalidad jurídica. Con todo, esta personalidad jurídica fue, como había sido hasta entonces, de derecho privado. Además, esta ley estableció una cierta estructura interna de los partidos, aun cuando todavía de manera muy elemental. Decía el Art. 20:

Art. 20. Los Partidos Políticos tendrán los derechos que las leyes acuerden a estas entidades y adquirirán personalidad ju-

${ }^{3}$ Esta ley está en: http://www.leychile.cl/Navegar?idNorma=27930\&bu scar $=$ ley + de + elecciones 
rídica por el hecho de inscribirse en el Protocolo de los Partidos Políticos que llevará el Director del Registro Electoral.

La solicitud de inscripción deberá hacerse por escrito ante el Director del Registro Electoral y firmarse por el Presidente y el Secretario de la Mesa Directiva Central designada en la asamblea constitutiva.

A la solicitud se acompañará copia autorizada ante Notario del Acta Constitutiva, que deberá contener el texto íntegro de los Estatutos aprobados en la referida asamblea y el nombre de los componentes de la primera Mesa Directiva Central de la colectividad.

Se acompañará, además, una nómina de por lo menos diez mil electores adherentes a la entidad, cuyas firmas o huellas dactiloscópicas aparezcan autorizadas ante Notario. Se aplicará con respecto a tal nómina lo prescrito en los tres últimos incisos del artículo 18.

Asimismo, se deberá acompañar un facsímil del símbolo o emblema que distinguirá al partido en la cédula electoral, para los efectos de lo dispuesto en el inciso cuarto del artículo 21 .

Ningún partido podrá adoptar un símbolo o emblema que induzca o pueda inducir a confusión con el de alguno de los partidos ya existentes.

No serán aceptados como símbolos o emblemas, y serán rechazados de plano por el Director del Registro Electoral, los que contengan palabras, frases o locuciones, y además los siguientes:

a) El escudo, la bandera o el emblema de la Nación;

b) Fotografías o reproducciones de la figura humana, $y$

c) Imágenes obscenas o contrarias a la moral, a las buenas costumbres o al orden público.

La Dirección del Registro Electoral desechará de plano toda solicitud que no cumpla con las exigencias señaladas. La resolución que se dicte será apelable ante el Tribunal Calificador de Elecciones, dentro de cinco días desde su notificación. La organización interna contemplará la existencia de una Mesa Directiva Central que será la autoridad superior del partido, la que estará integrada, a lo menos, por tres personas que harán las veces de presidente, secretario y tesorero.

Los Estatutos señalarán la denominación de la Mesa Directiva Central y la que corresponda a los cargos directivos mencionados. 
La persona que tenga a su cargo las funciones de presidente, cualquiera que sea la denominación que al cargo asigne el Estatuto, tendrá la representación legal del Partido, judicial y extrajudicialmente.

No podrán presentarse solicitudes de inscripción de un Partido dentro de los doscientos cuarenta días anteriores a la fecha de una elección ordinaria. En las elecciones extraordinarias no tendrán derecho a formular declaraciones de candidatos las colectividades que a la fecha de producirse el hecho que motiva la elección no hayan obtenido personalidad jurídica.

La solicitud de inscripción será publicada por la Dirección del Registro Electoral en el "Diario Oficial" una vez enterado en dicha Dirección por los solicitantes, el pago de esa publicación.

Dentro de los treinta días siguientes a la publicación mencionada, cualquier Partido Político podrá formular ante la Dirección del Registro Electoral oposición escrita a la inscripción del nuevo Partido.

La oposición será resuelta en primera instancia, dentro de los diez días siguientes a su presentación, por el Director del Registro Electoral, quien reunirá las pruebas y los antecedentes que estime del caso.

Dentro de los cinco días siguientes a la notificación de la resolución del Director del Registro Electoral, el opositor o el solicitante de la inscripción podrá reclamar ante el Tribunal Calificador de Elecciones, el cual resolverá también en el plazo de cinco días. Sólo se podrá aceptar una oposición fundada en el incumplimiento de las disposiciones de la Ley General de Elecciones.

Si no se dedujere oposición dentro del plazo legal, o si deducida ésta, quedare a firme la resolución que la rechaza, el Director del Registro Electoral dictará una resolución por la cual se declare la existencia legal del nuevo Partido Político, publicándola en el "Diario Oficial" y practicando en la misma fecha de la publicación la inscripción respectiva en el Protocolo a que se refiere el inciso primero de este artículo.

La personalidad jurídica de un Partido se extinguirá con la cancelación de la respectiva inscripción en el Protocolo de la Dirección del Registro Electoral.

La cancelación a que se refiere el inciso anterior sólo procederá en los casos de fusión o disolución de un Partido Político o cuando éste no alcanzare representación parlamentaria en cualquier elección ordinaria, a menos que dicho Partido 
conserve representación en el Senado. Esta facultad corresponderá ejercerla al Director del Registro Electoral.

Los Partidos Políticos con inscripción vigente podrán solicitar por escrito al Director del Registro Electoral cualquiera modificación a ésta, sea en lo referente al nombre o denominación de la colectividad, símbolo o emblema, a su domicilio, objetivos, organización interna, modificaciones en la composición de las Mesas Directivas Centrales, fusiones con los otros partidos, a sus bienes, como asimismo, a su disolución. El Director indicado procederá a practicar en el Protocolo las modificaciones pertinentes, siempre que éstas se hayan acordado en la forma y por los organismos del Partido que las respectivas normas estatutarias señalen.

En la tramitación de estas solicitudes se aplicará el procedimiento previsto en los incisos décimo a décimocuarto, inclusive, del presente artículo. Regirá también con respecto a dichas solicitudes la prohibición contenida en su inciso noveno.

Ningún Partido podrá adoptar un nombre que induzca a confusión con el de algunos de los Partidos ya existentes.

Se aplicará a los Partidos Políticos lo previsto en los artículos 549, 552, 555, 556 y 561 del Código Civil.

Estarán exentos de todo impuesto o contribución de cualquiera naturaleza, los documentos y actuaciones a que dé lugar la constitución e inscripción de los Partidos Políticos y los que se relacionen con la modificación de sus Estatutos.

Esta Ley 14.852 de 1962 fue, además, especialmente interesante porque reguló con una intensidad inédita a esa fecha la propaganda electoral. Llama la atención, eso sí, que la ley guardó silencio sobre el financiamiento electoral. Dispuso sobre la propaganda el Artículo 8 de la ley:

Art. $8^{\circ}$. En las elecciones de Regidores, Diputados o Senadores, o de Presidente de la República, la propaganda electoral se regirá por las siguientes disposiciones:

1) La propaganda electoral por avisos, carteles, letreros, telones, afiches, $\mathrm{u}$ otros similares y, en forma especial, la propaganda mural, sólo podrá efectuarse durante los 45 días que precedan al de la elección, si se trata de elecciones de Senadores, Diputados o Regidores, y durante los 90 días anteriores al del acto electoral, en el caso de elección de Presidente de la República. Dentro de dichos plazos en los radios urba- 
nos sólo podrá llevarse a efecto la propaganda de letreros, carteles, telones, afiches y otros similares en las calles, plazas y demás bienes nacionales de uso público, con autorización de la Municipalidad respectiva, la que designará lugares adecuados para ese efecto y los distribuirá equitativamente entre los distintos candidatos.

La propaganda electoral por la prensa o radio sólo podrá efectuarse durante los 15 días que preceden al de la elección, si se trata de elecciones de Senadores, Diputados o regidores, y durante los 45 días anteriores al del acto electoral en el caso de una elección de Presidente de la República.

Sin embargo, en las ciudades de más de cinco mil habitantes, queda prohibida la propaganda electoral por medio de carteles, letreros, telones y afiches.

Queda también prohibida la propaganda electoral con pinturas en los muros de edificios y en cierros definitivos o provisionales, salvo que el respectivo propietario la autorice. Asimismo, se prohibe la propaganda con pintura en los postes, puentes y en cualquiera otra obra o instalación de servicio público.

2) Las sedes oficiales de los partidos políticos acreditados en conformidad a la presente ley y sus secretarías de propaganda hasta un máximo de cinco en cada comuna, podrán exhibir en sus frontispicios letreros, telones, afiches u otra propaganda electoral de sus respectivos candidatos durante los 45 ó 90 días, según sea el caso, anteriores a la correspondiente elección.

Igual derecho tendrán los candidatos independientes.

En los campamentos mineros que determine el Presidente de la República, la respectiva empresa deberá proporcionar local para secretaría electoral a cada partido que haya presentado lista de candidatos en la circunscripción correspondiente.

3) Las Municipalidades deberán colocar y mantener en los 45 ó 90 días, según sea el caso, anteriores al de la elección, tableros o murales especiales, ubicados en algunos de los sitios públicos más frecuentados de su territorio comunal, donde figurarán la propaganda y todas las listas, debidamente individualizadas, de los candidatos que opten a la elección de que se trate, en el orden determinado por el artículo $22^{\circ}$ de la presente ley. En dichos tableros o murales, que tendrán un tamaño adecuado, se dispondrá del mismo espacio para cada lista. 
No podrá omitirse colocar estos carteles o murales en las circunscripciones electorales o localidades con más de 3.000 habitantes pertenecientes al territorio de la respectiva comuna, conforme lo determine el censo realizado el año 1960. En las ciudades que tengan más de 5.000 habitantes conforme a dicho censo, el número de estos tableros o murales no podrá ser inferior a 10.

Cuando no se dé cumplimiento íntegro y oportuno a las obligaciones señaladas en los incisos precedentes de este número, los responsables serán sancionados en la forma prevista en el inciso penúltimo del $\mathrm{N}^{\circ} 10$ ) de este artículo.

4) Queda prohibida toda propaganda electoral por medio de altos parlantes, sean éstos fijos o movibles, con la única excepción de la transmisión por altoparlantes de discursos pronunciados en concentraciones públicas.

5) El Cuerpo de Carabineros fiscalizará, salvo en lo referente a la prensa y radio, el cumplimiento de las disposiciones de los Nos 1), 2) y 4) de este artículo y procederá, de oficio o a petición de cualquiera persona, a retirar o suprimir los elementos de propaganda que contravengan dichas disposiciones.

De lo actuado a este respecto, se dará cuenta inmediata al Juez de Letras de Mayor Cuantía que corresponda.

Sin perjuicio de lo anterior, cualquier candidato, el Alcalde o cualquier Regidor de la municipalidad respectiva, podrá ocurrir ante el respectivo Juez de Letras de Mayor Cuantía a fin de que éste ordene dicho retiro o supresión. Los referidos elementos de propaganda caerán en comiso, el que será decretado por el respectivo Juez de Letras de Mayor Cuantía.

6) Queda prohibida, asimismo, toda propaganda electoral por medio del cinematógrafo, como también, la que pudiere efectuarse a través de la televisión, sin perjuicio, en este último caso, de los foros que se organicen, a los que tendrán igual acceso los diferentes candidatos, de acuerdo con las normas y espacios que para este objeto determine el Consejo de Rectores de las Universidades.

7) En el período que les está permitido hacer propaganda electoral, las radioemisoras deberán poner a disposición de los partidos políticos y de los grupos que patrocinen candidaturas independientes, un espacio de tiempo de una hora diaria, durante el cual se difundirá la propaganda pagada que ellos deseen contratar. 
El Reglamento determinará la manera en que los partidos políticos y los grupos que patrocinen candidaturas independientes tengan igual acceso a la propaganda política durante el espacio antes señalado.

Sin perjuicio de lo anterior, las empresas radiodifusoras podrán transmitir la propaganda electoral que libremente contraten con tal que, en conjunto con el espacio obligatorio, no destinen a ellas más de un $15 \%$ de su transmisión diaria.

La obligación del inciso primero no regirá para las estaciones de radiodifusión que se comprometan a que no harán propaganda en una determinada elección. Dicho compromiso deberá formularse por escrito ante la Dirección del Registro Electoral, por lo menos con un mes de anterioridad a la fecha en que determine la correspondiente prohibición.

Las tarifas que podrán cobrar las radioemisoras por sus espacios no podrán ser superiores a las ordinarias vigentes para propaganda comercial en los seis meses anteriores al término del período de la prohibición.

8) Las empresas periodísticas no podrán cobrar por la propaganda electoral de los partidos políticos o de los candidatos, tarifas superiores a las ordinarias vigentes para propaganda comercial en los seis meses anteriores al término del período de la prohibición.

9) Serán sancionados de acuerdo con el inciso penúltimo del $\mathrm{N}^{\circ} 10$ ), los agentes de instituciones públicas o privadas que, con motivo de donaciones o actos de asistencia social, realicen propaganda electoral.

10) Toda infracción a cualquiera de las obligaciones y prohibiciones que el presente artículo impone a los órganos de prensa, a las radioestaciones, a las estaciones de televisión y a los cinematógrafos, será sancionada con una multa a beneficio municipal de uno a diez sueldos vitales anuales del departamento de Santiago, la que se aplicará a la empresa propietaria o concesionaria del respectivo medio de difusión. Igual sanción se aplicará a la violación del compromiso a que se refiere el inciso tercero del $\mathrm{N}^{\circ} 7$ ).

La infracción a las demás obligaciones y prohibiciones que establece el presente artículo será sancionada con pena de prisión de uno a sesenta días.

Conocerá de las infracciones a que se refiere este número, el Juez de Letras de Mayor Cuantía en lo criminal del departamento correspondiente." 
Por otra parte, la Ley 14.852 dispuso que la Dirección del Registro Electoral debía instalar, algunos días antes de cada elección, carteles con la cédula de votación correspondiente, a fin de informar a la ciudadanía. Los partidos podían solicitar dichos carteles a la Dirección, pagando su valor. Disponía el último inciso de su Art. 25:

La Dirección del Registro Electoral entregará a los Partidos registrados y a los candidatos independientes el número de carteles que éstos soliciten en la declaración de la candidatura, previo pago de su valor. La entrega la hará, dentro del plazo de diez días, cuando se trate de elecciones unipersonales, y dentro del plazo de 40 días, cuando se trate de elecciones pluripersonales, contados ambos desde la expiración del término señalado para declarar las respectivas candidaturas.

La Ley 14.852 también reguló otros aspectos de la participación de los partidos en los procesos electorales. Por ejemplo, la obligación de que todo candidato al Congreso que sea apoyado por un partido político, debe pertenecer a dicho partido. Asimismo, los candidatos independientes no debían pertenecer a un partido durante los 180 días antes de su la presentación de su candidatura, por lo menos. El inciso tercero del Artículo 19 así lo mandaba:

... tratándose de declaraciones de Diputados o Senadores, es requisito que el candidato pertenezca al Partido Político que sustenta su candidatura a lo menos 180 días antes a la declaración, la que deberá ser jurada. La contravención a esta norma se sancionará con la nulidad de todos los votos de la lista. No podrán figurar como candidatos independientes personas que pertenezcan o hayan pertenecido hasta 180 días antes de la declaración respectiva a un Partido Político.

Tras esta ley de 1962, el siguiente acto normativo de importancia en relación con los partidos políticos — como se mencionó más arribafue la reforma constitucional aprobada en 1970 y que empezó a regir a principios de 1971. Se trata de la reforma mejor conocida como "Estatuto de Garantías Constitucionales", que se pactó entre la Democracia Cristiana y la Unidad Popular, como condición de la primera para votar en el Congreso Pleno por Salvador Allende como Presidente de la República. Pasemos a revisarla. 


\subsubsection{Estatuto de Garantías Constitucionales de 1970-1971}

La enjundia regulatoria constitucional que sobre los partidos políticos rige hoy, tiene su antecedente inmediato en esa reforma que fue dramática, como así lo atestigua el asesinato del Comandante en Jefe del Ejército poco antes de ser votada.

Es interesante el hecho de que, a pesar de garantizar la libertad de asociación y la libertad de los partidos políticos para organizarse, la reforma cambió el carácter jurídico de los partidos desde organizaciones de derecho privado, como fueron consideradas siempre, a organizaciones de derecho público. Sin embargo, es preciso apuntar aquí que nunca se les dio un régimen legislativo especial, como suele ocurrir con este tipo de personas. Otra cosa interesante fue la garantía que se consagró en el sentido de que los partidos fueran propietarios de diarios, revistas y radios. Asimismo, se garantizó el acceso de los partidos a los medios de comunicación de propiedad estatal. Veamos las disposiciones:

Art. $9^{\circ}$. - La Constitución asegura a todos los ciudadanos el libre ejercicio de los derechos políticos, dentro del sistema democrático y republicano. Todos los chilenos pueden agruparse libremente en partidos politicos, a los que se reconoce la calidad de personas jurídicas de derecho público y cuyos objetivos son concurrir de manera democrática a determinar la política nacional.

Los partidos politicos gozarán de libertad para darse la organización interna que estimen conveniente, para definir y modificar sus declaraciones de principios y programas y sus acuerdos sobre política concreta, para presentar candidatos en las elecciones de regidores, diputados, senadores y Presidente de la República, para mantener secretarías de propaganda y medios de comunicación y, en general, para desarrollar sus actividades propias. La ley podrá fijar normas que tengan por exclusivo objeto reglamentar la intervención de los partidos políticos en la generación de los Poderes Públicos.

Los partidos políticos tendrán libre acceso a los medios de difusión y comunicación social de propiedad estatal o controlados por el Estado, en las condiciones que la ley determine, sobre la base de garantizar una adecuada expresión a las distintas corrientes de opinión en proporción a los sufragios obtenidos por cada una en la última elección general de diputados y senadores o regidores". 
Y la otra disposición pertinente, inciso quinto del Número 3 del Art. 10:

Toda persona natural o jurídica, especialmente las universidades y los partidos políticos, tendrán el derecho de organizar, fundar y mantener diarios, revistas, periódicos o estaciones transmisoras de radio, en las condiciones que establezca la ley. Sólo por ley podrá modificarse el régimen de propiedad y de funcionamiento de esos medios de comunicación. La expropiación de los mismos podrá únicamente realizarse por ley aprobada, en cada Cámara, con el voto conforme de la mayoría de sus miembros en ejercicio.

Tras el golpe militar de 1973, los partidos políticos fueron proscritos (o se autodisolvieron), clausurándose la vida partidaria —al menos la vida no clandestina - hasta finales de los años ochenta. La reactivación de la vida partidaria se hizo, primero, con la Constitución de 1980 y, luego, con la Ley 18.603 de 1987, (Ley Orgánica Constitucional de Partidos Políticos), más otras leyes que, como la LOC 18. 700, de Votaciones Populares y Escrutinios, conformaron lo que en la época se llamó "las leyes políticas". A continuación, se repasa lo que la Constitución de 1980 dispuso para los partidos políticos. Luego de esto, se analiza la Ley 18.603, LOC de Partidos Políticos. Esta es la regulación vigente hoy. Cualquier reforma, debería dirigirse hacia ella.

\subsubsection{Constitución de 1980}

A diferencia del Estatuto de Garantías Constitucionales de 19701971, que fue especialmente amable con los partidos, el texto constitucional de 1980 fue, comparativamente hablando, algo más hostil hacia ellos. En general, ese texto lo que hace es poner límites a los partidos, trata de circunscribirlos.

Por lo pronto, ya no les da personalidad jurídica de derecho público, como se hizo en esa reforma anterior. Asimismo, se los incorpora al mecanismo que se denominó como "democracia protegida". Los dos primeros incisos del Artículo 8 prescribían:

Todo acto de persona o grupo destinado a propagar doctrinas que atenten contra la familia, propugnen la violencia o una concepción de la sociedad, del Estado o del orden jurídico, de 
carácter totalitario o fundada en la lucha de clases, es ilícito y contrario al ordenamiento institucional de la República.

Las organizaciones y los movimientos o partidos políticos que por sus fines o por la actividad de sus adherentes tiendan a esos objetivos, son inconstitucionales.

Por su parte, el Artículo 18 los pone en igualdad de condiciones que los independientes a la hora de participar en el juego electoral. Así lo disponía:

Habrá un sistema electoral público. Una ley orgánica consti-
tucional determinará su organización y funcionamiento, re-
gulará la forma en que se realizarán los procesos electorales
y plebiscitarios, en todo lo no previsto por esta Constitución
y, garantizará siempre la plena igualdad entre los indepen-
dientes y los miembros de partidos políticos tanto en la pre-
sentación de candidaturas como en su participación en los
señalados procesos.
El resguardo del orden público durante los actos electorales y
plebiscitarios corresponderá a las Fuerzas Armadas y Carabi-
neros del modo que indique la ley.

Ahora bien, el Artículo 19 No 15 estableció el derecho a asociarse en general y, en particular, el derecho a asociarse en partidos políticos. Sin embargo, acto seguido, la Constitución repitió su esfuerzo por circunscribirlos.

El derecho de asociarse sin permiso previo.

Para gozar de personalidad jurídica, las asociaciones deberán constituirse en conformidad a la ley.

Nadie puede ser obligado a pertenecer a una asociación. Prohíbense las asociaciones contrarias a la moral, al orden público y a la seguridad del Estado.

Los partidos políticos no podrán intervenir en actividades ajenas a las que les son propias ni tener privilegio alguno o monopolio de la participación ciudadana; sus registros y contabilidad deberán ser públicos; las fuentes de su financiamiento no podrán provenir de dineros, bienes, donaciones, aportes ni créditos de origen extranjero; sus estatutos deberán contemplar las normas que aseguren una efectiva democracia interna. Una ley orgánica constitucional regulará las demás materias que les conciernan y las sanciones que se aplicarán por el incumplimiento de sus preceptos, dentro de las cuales 
podrá considerar su disolución. Las asociaciones, movimientos, organizaciones o grupos de personas que persigan o realicen actividades propias de los partidos políticos sin ajustarse a las normas anteriores son ilícitos y serán sancionados de acuerdo a la referida ley orgánica constitucional.

Luego, al tratar sobre el ámbito de competencia del Tribunal Constitucional, el Artículo 82, en su número 7, lo facultaba para declarar inconstitucionales los partidos que vulneraban lo dispuesto en el Artículo 8, esto es, el mecanismo de "democracia protegida":

Declarar la inconstitucionalidad de las organizaciones, y de los movimientos o partidos políticos, en conformidad a lo dispuesto en el artículo $8^{\circ}$ de esta Constitución ${ }^{4}$.

Este fue el contexto constitucional en el que se dictó la Ley 18.603, LOC de Partidos Políticos, la primera norma legislativa - la primera norma jurídica, en realidad - que en Chile reguló sistemáticamente a los partidos. Antes de ir a ella, sin embargo, estas líneas se dirigirán a la reforma constitucional de 1989, que siguió delineando el marco regulatorio constitucional en torno a los partidos, y la de 2010, que introdujo la posibilidad de elecciones primarias, terminando de configurar dicho marco.

\subsubsection{La reformas constitucionales de 1989 y 2010}

Esta reforma fue importante para la materia que nos interesa, pues, como se acaba de decir, termina por definir la regulación constitucional de los partidos, regulación que, fundamentalmente, está vigente hoy.

La lógica de esta reforma fue más o menos parecida al texto original, en el sentido de que se buscó delimitar, circunscribir, a los

${ }^{4}$ Una última disposición, esta vez no restrictiva, estaba en el cuarto inciso del Art. 51 y se refería al reemplazo de las vacantes de parlamentarios: "Los parlamentarios elegidos como independientes no serán reemplazados. Los parlamentarios elegidos como independientes que hubieren postulado integrando lista en conjunto con uno o más partidos políticos, serán reemplazados por el ciudadano que señale el partido indicado por el respectivo parlamentario al momento de presentar su declaración de candidatura. El reemplazante deberá reunir los requisitos para ser elegido diputado o senador, según el caso." 
partidos. Se derogó el Artículo 8 y su "democracia protegida", pero se agregaron los siguientes incisos al No 15 del Artículo 19:

La Constitución Política garantiza el pluralismo político. Son inconstitucionales los partidos, movimientos $\mathrm{u}$ otras formas de organización cuyos objetivos, actos o conductas no respeten los principios básicos del régimen democrático y constitucional, procuren el establecimiento de un sistema totalitario, como asimismo aquellos que hagan uso de la violencia, la propugnen o inciten a ella como método de acción política. Corresponderá al Tribunal Constitucional declarar esta inconstitucionalidad.

Sin perjuicio de las demás sanciones establecidas en la Constitución o en la ley, las personas que hubieren tenido participación en los hechos que motiven la declaración de inconstitucionalidad a que se refiere el inciso precedente, no podrán participar en la formación de otros partidos políticos, movimientos $\mathrm{u}$ otras formas de organización política, ni optar a cargos públicos de elección popular ni desempeñar los cargos que se mencionan en los números 1) a 6) del artículo 57 , por el término de cinco años, contado desde la resolución del Tribunal. Si a esa fecha las personas referidas estuvieren en posesión de las funciones o cargos indicados, los perderán de pleno derecho.

Las personas sancionadas en virtud de este precepto no podrán ser objeto de rehabilitación durante el plazo señalado en el inciso anterior. La duración de las inhabilidades contempladas en dicho inciso se elevará al doble en caso de reincidencia.

Asimismo, se determinó la reserva con que debe manejarse el registro de los partidos. Dispuso esta reforma:

En el artículo 19 , número $15^{\circ}$, inciso quinto, reemplázanse las palabras "sus registros y contabilidad deberán ser públicos" por las siguientes frases: "la nómina de sus militantes se registrará en el servicio electoral del Estado, el que guardará reserva de la misma, la cual será accesible a los militantes del respectivo partido; su contabilidad deberá ser pública.

En ausencia del Artículo 8, derogado como recién se apuntó, fue modificada la disposición correspondiente a fin de que el Tribunal Constitucional pudiera declarar correspondiente la inconstitucionalidad: 
Declarar la inconstitucionalidad de las organizaciones y de los movimientos o partidos políticos, como asimismo la responsabilidad de las personas que hubieren tenido participación en los hechos que motivaron la declaración de inconstitucionalidad, en conformidad a lo dispuesto en los incisos sexto, séptimo y octavo del número $15^{\circ}$ del artículo 19 de esta Constitución...

Y luego, la siguiente reforma del Artículo 23 también buscó delimitar el campo de acción de los partidos, separando las actividades partidistas de las gremiales:

Art. 23. Los grupos intermedios de la comunidad y sus dirigentes que hagan mal uso de la autonomía que la Constitución les reconoce, interviniendo indebidamente en actividades ajenas a sus fines específicos, serán sancionados en conformidad a la ley. Son incompatibles los cargos directivos superiores de las organizaciones gremiales con los cargos directivos superiores, nacionales y regionales, de los partidos políticos.

La ley establecerá las sanciones que corresponda aplicar a los dirigentes gremiales que intervengan en actividades político partidistas y a los dirigentes de los partidos políticos, que interfieran en el funcionamiento de las organizaciones gremiales y demás grupos intermedios que la propia ley señale.

En enero de 2010, se publicó la reforma que introdujo la posibilidad de primarias, en el No 15 del Artículo 19 de la Constitución:

Una ley orgánica constitucional establecerá un sistema de elecciones primarias que podrá ser utilizado por dichos partidos para la nominación de candidatos a cargos de elección popular, cuyos resultados serán vinculantes para estas colectividades, salvo las excepciones que establezca dicha ley. Aquellos que no resulten elegidos en las elecciones primarias no podrán ser candidatos, en esa elección, al respectivo cargo. Una ley orgánica constitucional regulará las demás materias que les conciernan y las sanciones que se aplicarán por el incumplimiento de sus preceptos, dentro de las cuales podrá considerar su disolución.

En definitiva, el Artículo $19 \mathrm{~N}^{\circ}$ 15, en el que está el centro de la regulación constitucional de los partidos, ha quedado así: 
$15^{\circ}$.- El derecho de asociarse sin permiso previo.

Para gozar de personalidad jurídica, las asociaciones deberán constituirse en conformidad a la ley.

Nadie puede ser obligado a pertenecer a una asociación.

Prohíbense las asociaciones contrarias a la moral, al orden público y a la seguridad del Estado.

Los partidos políticos no podrán intervenir en actividades ajenas a las que les son propias ni tener privilegio alguno o monopolio de la participación ciudadana; la nómina de sus militantes se registrará en el servicio electoral del Estado, el que guardará reserva de la misma, la cual será accesible a los militantes del respectivo partido; su contabilidad deberá ser pública; las fuentes de su financiamiento no podrán provenir de dineros, bienes, donaciones, aportes ni créditos de origen extranjero; sus estatutos deberán contemplar las normas que aseguren una efectiva democracia interna. Una ley orgánica constitucional establecerá un sistema de elecciones primarias que podrá ser utilizado por dichos partidos para la nominación de candidatos a cargos de elección popular, cuyos resultados serán vinculantes para estas colectividades, salvo las excepciones que establezca dicha ley. Aquellos que no resulten elegidos en las elecciones primarias no podrán ser candidatos, en esa elección, al respectivo cargo. Una ley orgánica constitucional regulará las demás materias que les conciernan y las sanciones que se aplicarán por el incumplimiento de sus preceptos, dentro de las cuales podrá considerar su disolución.

Las asociaciones, movimientos, organizaciones o grupos de personas que persigan o realicen actividades propias de los partidos políticos sin ajustarse a las normas anteriores son ilícitos y serán sancionados de acuerdo a la referida ley orgánica constitucional. La Constitución Política garantiza el pluralismo político. Son inconstitucionales los partidos, movimientos u otras formas de organización cuyos objetivos, actos o conductas no respeten los principios básicos del régimen democrático y constitucional, procuren el establecimiento de un sistema totalitario, como asimismo aquellos que hagan uso de la violencia, la propugnen o inciten a ella como método de acción política. Corresponderá al Tribunal Constitucional declarar esta inconstitucionalidad.

Sin perjuicio de las demás sanciones establecidas en la Constitución o en la ley, las personas que hubieren tenido participación en los hechos que motiven la declaración de 
inconstitucionalidad a que se refiere el inciso precedente, no podrán participar en la formación de otros partidos políticos, movimientos u otras formas de organización política, ni optar a cargos públicos de elección popular ni desempeñar los cargos que se mencionan en los números 1) a 6) del artículo 57, por el término de cinco años, contado desde la resolución del Tribunal. Si a esa fecha las personas referidas estuvieren en posesión de las funciones o cargos indicados, los perderán de pleno derecho.

Las personas sancionadas en virtud de este precepto no podrán ser objeto de rehabilitación durante el plazo señalado en el inciso anterior. La duración de las inhabilidades contempladas en dicho inciso se elevará al doble en caso de reincidencia".

\subsection{PROPUESTAS DE REFORMAS INSTITUCIONALES EN TORNO A LA LOC DE PARTIDOS POLÍTICOS}

\subsubsection{La importancia de una reforma sistémica}

Existe una serie de disposiciones constitucionales y legales que afectan directamente la configuración y el accionar del sistema de partidos políticos, como se reseñó en la sección anterior. Como bien señala el trabajo de Richard Katz contenido en este Informe*, el concepto "ley de partido" (party law) puede interpretarse en sentido amplio o en sentido restringido. En sentido amplio, debe considerarse dentro de él toda aquella normativa que afecta a los partidos políticos, como sistema electoral, distritos, registro de votantes, mecanismos de sufragio, primarias, financiamiento de campañas, entre otras. En sentido restringido, en cambio, solo se considera las leyes que regulan la organización específica de los partidos en tanto instituciones.

En el caso de Chile, la Ley 18.603 Orgánica Constitucional de Partidos Políticos es el cuerpo legal que regula el aspecto organizacio-

* Aquí y más adelante, en el texto y notas, se hace referencia a trabajos que forman parte del Informe publicado en Democracia con Partidos, editado por Francisco Javier Díaz y Lucas Sierra (2012). (N. del E.) 
nal, constitución y funcionamiento interno de estas organizaciones. Pero existen otras materias que afectan a los partidos políticos porque tienen que ver, en general, con la actividad política. Estas otras materias que son reguladas por leyes distintas — como la Ley 19.884 sobre Transparencia, Límite y Control del Gasto Electoral, o la Ley 18.700 de Votaciones Populares y Escrutinios- o bien por la Constitución Política de la República. Asimismo, se discute en estos momentos ante el Congreso Nacional una normativa que formaliza y subsidia las elecciones primarias al interior de los partidos políticos y pactos electorales.

Una de las principales conclusiones que arrojan los estudios realizados en el marco de este Informe, es que la reforma al sistema político en general, y a los partidos políticos en particular, debe ser hecha teniendo en cuenta el contexto institucional completo. Esto no significa que todo el contexto institucional deba ser reformado al mismo tiempo, sino solo significa tener en cuenta que la ley de partidos, así como las demás leyes sobre la política, forman un sistema al interior del cual hay consecuencias recíprocas. Por esto, la visión sistémica que este informe propone no es, necesariamente, un big bang: no propone hacer todo de nuevo y, menos, hacerlo todo al mismo tiempo. La idea es evitar reformas parciales que puedan terminar siendo contraproducentes para la calidad de la democracia, a pesar de lo loables que puedan ser los objetivos de corto alcance de estas.

En el caso chileno, lo que este Informe detecta (en línea con otros trabajos sobre la materia) es una preocupante caída en la adhesión y representatividad de los partidos, lo que redunda en una pérdida de legitimidad de todo el sistema político.

Según muestran diversos estudios de opinión pública, los partidos políticos chilenos se encuentran entre las instituciones menos apreciadas por la ciudadanía. A nivel continental, los partidos chilenos son los que cuentan con menor identificación, situación que se viene agravando en los últimos años ${ }^{5}$. Esta mala percepción de los partidos, y más en general, de todas las instituciones políticas, se manifiesta también en la creciente abstención electoral que se da en el país. Sea porque los chilenos no se inscribían en los registros electorales (cuestión que cambia producto de la ley de inscripción automática); sea porque

${ }^{5}$ El trabajo de Luna y Rosenblatt en este Informe da cuenta de evidencia latinoamericana en este sentido. 
los inscritos no concurrían a votar; o sea porque concurriendo, votaban nulo o blanco, lo cierto es que poco más del $50 \%$ de la población mayor de 18 años participaba válidamente en las elecciones. Históricamente, la tendencia ha venido a la baja. La reciente introducción de la inscripción automática y voto voluntario genera una incógnita respecto de dicha tendencia: es posible que la inscripción automática aumente el número absoluto de votantes (el padrón electoral crece en más de cinco millones de ciudadanos, pasándose de ocho millones doscientos mil electores inscritos en los registros electorales, a trece millones trescientos mil personas habilitadas automáticamente para votar, aproximadamente), pero el voto voluntario genera una incertidumbre sobre el número de nuevos y antiguos votantes que efectivamente vayan a votar el día de la elección.

Por todo ello, en este Informe se proponen reformas de diversa índole. La mayoría están orientadas a la organización y funcionamiento que la ley hace de los partidos políticos. Pero también se hacen propuestas a otros cuerpos legales, incluyendo la Constitución, de manera de garantizar un conjunto de principios generales que el Informe estima indispensable para que los partidos favorezcan una democracia de calidad, como son la representatividad, participación, democracia interna, rendición de cuentas, consistencia programática, una mayor representación política femenina, así como una transparente relación entre dinero, intereses y política. Las propuestas sobre estas otras normas jurídicas se desarrollan a continuación.

\subsubsection{Reformas a la Constitución y leyes complementarias que tienen incidencia directa en los partidos políticos}

Como se señala en la sección 2.1. de este Informe, la Constitución de 1980 entrega algunos lineamientos normativos para los partidos políticos, a propósito de la garantía constitucional del derecho de asociación contenida en el artículo 19 número 15. A partir del inciso tercero de dicho precepto, se entrega una regulación genérica de los partidos y se encomienda a una ley orgánica constitucional regular las materias que les conciernen a los partidos, así como las sanciones a su incumplimiento. A su vez, ordena que otra ley orgánica constitucional regule el procedimiento de elecciones primarias al que se pueden someter los partidos. Sin embargo, en la Constitución y en sus leyes complementa- 
rias se encuentran otro tipo de normas que afectan directamente a los partidos políticos, como son, por ejemplo, el tamaño y conformación de las cámaras, el sistema electoral, el financiamiento de la política, la reelección y el sistema de reemplazo de vacantes.

Hay dos materias institucionales muy relevantes que tienen relación indirecta con el sistema de partidos políticos. La primera se refiere a las normas que reglan la relación entre Ejecutivo y Legislativo, las que pueden tener enorme influencia en el sistema de partidos, toda vez que estos se hacen más relevantes en los sistemas parlamentaristas que en los sistemas presidencialistas. La segunda se trata del sistema de quórums supramayoritarios para determinadas leyes que existe en nuestro ordenamiento constitucional, el que afecta la representatividad del sistema político, al crear un poder de veto a favor de la fuerza que es minoría electoral. Por tener una relación indirecta, sin embargo, estos dos temas no son abordados en este Informe.

\section{Conformación del Congreso y sistema electoral}

El sistema electoral chileno se encuentra establecido en la Ley 18.700, Ley Orgánica Constitucional de Votaciones Populares y Escrutinios. Por su carácter de ley orgánica constitucional, la aprobación, modificación o derogación de esa ley requiere el voto conforme de 4/7 de los miembros en ejercicio de ambas cámaras. Sin embargo, producto de las reformas constitucionales de 2005, se dejó establecido que cualquier modificación que diga relación con el número de senadores, las circunscripciones existentes y el sistema electoral vigente, requerirá del voto conforme de $3 / 5$ de los diputados y senadores en ejercicio (según reza el artículo 13 transitorio de la Constitución).

El sistema electoral es el mismo tanto para senadores como diputados. Técnicamente, se trata de un sistema de carácter proporcional, con fórmula D'Hondt, de magnitud distrital binominal — esto es, se eligen dos cargos en cada distrito o circunscripción. La literatura es mayoritaria en destacar una serie de efectos perniciosos que posee el actual sistema electoral, entre ellos: en primer lugar, se critica al sistema binominal por no favorecer la representatividad. Dada la mecánica del sistema, la segunda mayoría tiende a ser premiada en desmedro de la primera mayoría (la que pierde el "excedente" de votos, pues para obtener los dos escaños del distrito debe doblar en votos a la segunda lista), 
y en desmedro de la tercera mayoría (la que a pesar de lograr un porcentaje importante en el distrito, no obtiene ningún cupo). Esta mecánica genera un empate artificial entre las dos primeras listas, tanto a nivel distrital como a nivel agregado. Por otro lado, como bien destaca Arturo Valenzuela en su trabajo, el sistema binominal reduce excesivamente la oferta partidaria en un país de tradición multipartidista, impidiendo de esa manera que el elector tenga un real menú político de donde elegir. Asimismo, cabe señalar que la baja magnitud distrital del sistema chileno merma la representación política de la mujer en los cargos electos ${ }^{6}$.

En segundo término, se critica el sistema binominal porque disminuye la competencia. Como se explicó arriba, la mecánica del sistema fuerza un empate en escaños entre las dos primeras listas, lo que transforma las elecciones en eventos escasamente competitivos. Esta mecánica ha hecho que de 720 escaños de diputados que han sido concursados desde 1990 hasta 2010, en solo catorce oportunidades han sido electos diputados yendo por fuera de alguno de los dos pactos principales. De 132 escaños senatoriales, solo en una ocasión ha sido electo un senador yendo por fuera de los dos pactos principales.

Esta mecánica ha generado una dinámica aun más perversa: como las listas saben que existe una altísima probabilidad de elegir uno de los dos escaños en cada distrito, ellas han comenzado a repartirse en el papel los distintos distritos y "blindar" candidatos (por la vía de no presentarles compañeros de lista, o bien presentar un acompañante evidentemente poco competitivo). Cuando las coaliciones se dan cuenta de que la competencia real es al interior de ellas y no con la lista contraria, surgen los acuerdos colusivos para evitar dicha contienda intestina, lo que significa que los partidos terminan prácticamente designando al candidato que es finalmente electo. Y como apuntan en sus trabajos para este Informe, Arturo Valenzuela, y Juan Pablo Luna y Fernando Rosenblatt, se aprecia una tendencia a que sean caudillos locales los

${ }^{6}$ A pesar de que las mujeres constituyen la mayoría del padrón electoral, solo el $14,2 \%$ de los asientos en la Cámara de Diputados y el 13,2\% del Senado son ocupados por mujeres. El porcentaje de mujeres en ambas cámaras es inferior al promedio mundial de participación femenina en las asambleas legislativas $(19,5 \%)$ y supera solamente el promedio de los Estados Árabes $(10,7 \%)$. En la región latinoamericana, en cámaras bajas, Chile se encuentra lejos de países como Nicaragua (40,2\%), Costa Rica $(38,6 \%)$, Argentina $(37,4 \%)$, Ecuador (32,3\%) y México (26,2\%), según datos de la Inter-Parliamentary Union, documento electrónico Women in National Parliaments. Comparative data by country, 2012. 
que logran la nominación de sus partidos, como verdaderos empresarios políticos individuales, lo que redunda en una baja lealtad partidaria.

En definitiva, el elector no tiene, en los hechos, el veredicto final, y su posibilidad de elegir se limita seriamente. La competencia entre listas es escasa. Los partidos prácticamente nominan a los electos, pero son los caudillos locales quienes tienden a lograr la nominación. Todo ello afecta a la calidad de la democracia y termina por dañar la función de los partidos, la lealtad partidaria y la consistencia programática. En la práctica, el binominal hace que la competencia que produce no sea entre coaliciones políticas, sino que al interior de estas coaliciones. En este sentido, el sistema binominal es fratricida, lo que le impone un costo excesivamente alto a la asociatividad política.

Por todas estas razones, este Informe propone una revisión a fondo del sistema binominal vigente y su reemplazo por un sistema que fomente mayor competencia entre los candidatos y partidos, pero que a su vez vele por una adecuada representatividad. Encontrar un sistema que genere un mínimo consenso será una ardua tarea para los partidos. Para evitar suspicacias, se propone dilatar la entrada en vigencia de esta reforma, de manera tal que comience a regir en una legislatura posterior a la que la aprobó.

A pesar de que la literatura política y académica es mayoritaria en destacar las falencias del sistema binominal, no existe consenso en cómo reformarlo ni hacia qué sistema avanzar. La experiencia comparada muestra que existen casi tantas variantes de sistemas electorales como democracias en el mundo.

Una alternativa de reforma es mudarse hacia un sistema mayoritario, al estilo de Estados Unidos o el Reino Unido, donde se elige solo a la primera mayoría en distritos y circunscripciones de magnitud igual a uno, o bien, como en el caso del Senado estadounidense, donde se eligen dos senadores en cada estado, pero de manera alternada - es decir, en una elección uno y a la otra elección el otro. El sistema mayoritario, si bien favorece la competencia y simplifica la determinación del ganador - lo que es fácilmente entendible por la ciudadanía - tiene el problema de generar resultados desproporcionados, afectando la representatividad. Esto puede ser especialmente contraproducente en un país de tradición multipartidista como es Chile.

Una segunda alternativa es la propuesta de sistema proporcional corregido o atenuado, como explicó la Comisión Boeninger en 2006 
— propuesta que ha sido recogida por la Concertación, y más recientemente, por el documento de la Democracia Cristiana y Renovación Nacional. Se trata de un sistema proporcional de magnitud distrital variable (pero superior a dos). Se basa en el concurso de listas de candidatos presentadas por los partidos o pactos de partidos. Se puede discutir si se trata de listas cerradas (donde es el partido el que determina el orden de los candidatos a elegir dentro de la lista) o si se trata de listas abiertas (donde el elector puede elegir votar genéricamente por el partido o pacto, o bien, por un candidato específico dentro de cada partido o pacto). La primera da mayor poder al partido, mientras que la segunda (la que promueve Valenzuela en su trabajo para este Informe, y que es la que existió en Chile antes de 1973) entrega un mayor radio de acción al político individual, aunque enriquece la oferta. La fórmula electoral debiera continuar siendo la fórmula D'Hondt (que favorece la formación de grandes bloques).

Una tercera alternativa es explorar el camino de los sistemas mixtos, es decir, aquellos que combinan una elección mayoritaria y una elección proporcional por la vía de dos listas paralelas, o bien, por la vía de escaños que compensan un eventual resultado desproporcional. Este tipo de sistema existe en países como Alemania, Nueva Zelanda, México, o en países de reciente democratización, como Croacia, Hungría, Rusia o Marruecos, y ha sido objeto de propuesta por parte de dirigentes políticos de partidos de gobierno y oposición en Chile. Los sistemas mixtos tienen algunas virtudes: primero, ayudan a mantener la competitividad y simpleza de los sistemas mayoritarios, pero moderan sus resultados; segundo, evitan la fragmentación del sistema de partidos y favorecen la conformación de bloques; y, tercero, ayudan a corregir la posible desproporcionalidad inherente a los sistemas mayoritarios por la vía de la lista paralela, especialmente si se trata de listas compensatorias de los resultados de la elección mayoritaria. El principal problema de estos sistemas de doble lista es más bien práctico, pues generan dos tipos de legisladores: los parlamentarios "con distrito" y los parlamentarios "sin distrito", produciéndose odiosas diferencias entre unos y otros.

Ambos sistemas (proporcional y mixto) tienen una segunda externalidad positiva: la literatura comparada indica que en ese tipo de sistema tiende a equilibrarse de mejor manera la representación de género, en comparación con los sistemas mayoritarios y/o aquellos de baja magnitud distrital, como es el binominal chileno. 
Forma y proporcionalidad de distritos y circunscripciones

Tan importante como la magnitud distrital y la fórmula electoral, es el dibujo territorial de los distritos y la población que agrupa cada uno de ellos. Es importante que los distritos posean una cierta lógica territorial y que se ajusten a alguna unidad administrativa (como es la comuna). A su vez, es importante que, sobre todo a nivel de Cámara Baja, los distritos guarden cierta correspondencia entre ellos con respecto al número de habitantes.

La literatura comparada documenta la práctica de "gerrymandering", es decir, la práctica de manipular resultados electorales por la vía de dibujar un distrito electoral en el mapa basándose en los resultados de elecciones pasadas. De esa forma, los expertos electorales logran armar distritos de evidente conveniencia para sus intereses, aun cuando el dibujo del distrito no haga sentido lógico alguno ni guarde relación con unidades administrativas previamente establecidas. En Chile, los distritos y circunscripciones se construyen a partir de la comuna. El problema surge al agrupar comunas para efectos de dibujar el distrito o circunscripción respectiva.

Otro problema serio es la disparidad de población que puede existir entre distritos. Los distritos electorales que fueron establecidos por la Ley 18.700 en 1988 ya contenían una fuerte disparidad de población entre distritos urbanos y rurales. Además, desde 1988 no se ha actualizado esa configuración, por lo que se han producido fuertes cambios demográficos y migratorios que no fueron recogidos por el mapa electoral. Estos cambios recién han sido reflejados en toda su magnitud a propósito de la actualización del padrón electoral producto de la ley de inscripción automática. De esta forma, se ha acrecentado la fuerte disparidad entre comunas densamente pobladas y otras de menor población.

Por ello, este Informe propone actualizar el mapa electoral del país y crear un mecanismo que lo revise periódicamente en función de la población que abarca el determinado territorio

En los países que poseen un sistema electoral mayoritario (donde se elige sólo un representante por distrito), este mecanismo se realiza creando comisiones especiales de redistritaje en el servicio electoral, en las que participan apoderados de los partidos, quienes van ajustando los contornos de los distritos según las variaciones en la población. Los 
procesos de redistritaje se realizan por lo general cada diez años, en consideración a los datos de población que arroja el proceso de censo nacional.

En los países que poseen un sistema proporcional, en cambio, dado que la magnitud distrital puede ser variable, lo que se hace es adecuar automáticamente el número de escaños a elegir según los cambios en la población que habita en dicho distrito. Este es el sistema que se utiliza en Chile para las elecciones de concejales, donde cada municipio elige entre seis, ocho o diez concejales según varíe el número de votantes de la comuna.

\section{El problema de la reelección}

Uno de los efectos del sistema electoral binominal es la personalización de la política partidista en los territorios, lo que se ve potenciado por la baja competitividad del sistema. Es decir, el político local se hace cada vez más fuerte, logrando presionar al partido por su nominación, debilitándose su vínculo con el partido y por ende, disminuyendo la capacidad del partido de fijar una línea política y programática coherente en todo el país. Esto impide, además, que se produzca una renovación de cuadros en los partidos, provocando frustración en las nuevas generaciones de militantes, así como de las mujeres, las que, como se vio, se encuentran claramente subrepresentadas en ambas cámaras.

Como señala Arturo Valenzuela en este Informe, parte de esta tendencia se origina en la reelección del parlamentario, lo que le permite irse fortaleciendo en el tiempo, especialmente ante la ausencia de elecciones primarias y considerando el sistema binominal. El trabajo de Claudio Agostini para este Informe demuestra que la incumbencia genera una ventaja significativa a la hora de la competencia electoral.

Pero, por otra parte, como el propio Valenzuela también señala, los límites a la reelección tienen desventajas. El conocimiento del proceso legislativo toma tiempo, si la reelección se prohíbe o limita, por lo que ese esfuerzo se pierde o se desaprovecha, respectivamente. Además, la reelección permite el desarrollo de verdaderas carreras política asociadas a la actividad parlamentaria y municipal, y, por lo mismo, permite la profesionalización de la política. La reelección, en fin, permite, también, la expresión de una genuina preferencia política por un incumbente. 
¿Qué hacer frente a este problema? La pregunta no es fácil. Si se prohíbe la reelección en forma absoluta de un parlamentario, se pierde en exceso el esfuerzo invertido en su aprendizaje del complejo proceso legislativo y se desalienta, en exceso también, la alternativa de dedicarse profesionalmente a la política. La verdadera disyuntiva, entonces, está entre dejar las cosas como están (reelección ilimitada) o establecer algún límite a la reelección.

Si el sistema político tuviera grados de competencia más altos que los relativamente bajos que hoy exhibe, especialmente en razón del binominal, la alternativa de dejar las cosas como están — reelección indefinida - tendría mayor fuerza. Pero como el binominal genera reducida competencia, reforzando electoralmente a los incumbentes, la posibilidad de establecer algún límite a la reelección de diputados cobra una fuerza relativamente mayor.

En este último caso, entonces, con el sistema binominal actual, una alternativa podría ser el limitar el número de reelecciones de diputados y senadores. Para esto se puede hacer una distinción entre autoridades. En el caso de los diputados, el límite puede tres reelecciones (esto es, cuatro períodos consecutivos, dieciséis años como máximo). En el caso de los senadores, el límite puede ser una reelección (esto es, dos períodos consecutivos, dieciséis años como máximo). El período de los senadores en Chile es inusualmente alto (ocho años), de ahí la necesidad de tan drástica limitación.

El caso de la autoridad municipal es distinto. Ahí existe un sistema electoral plenamente competitivo para alcaldes (uninominal) y plenamente proporcional para concejales. Sin embargo, se propone limitar reelecciones a ese nivel en atención al riesgo de captura y la posibilidad de generar clientelas por parte de la autoridad local. Por lo mismo, se propone limitar a tres el número de reelecciones de los alcaldes y concejales (es decir, ejercer cuatro períodos).

\section{Sistema de reemplazos de parlamentarios que dejan vacante}

En opinión de este Informe, el sistema que contempla la Constitución Política para suplir las vacancias que pudieran producirse en el Congreso Nacional, sea por muerte, renuncia o cesación, no ayuda a restablecer la credibilidad de los partidos políticos. 
El artículo 51, inciso final, prohíbe expresamente la realización de elecciones complementarias para llenar una vacante. Ese mismo artículo, en sus incisos $3^{\circ}, 4^{\circ}$ y $5^{\circ}$, establece que la vacante producida debe ser provista por el partido político al que pertenecía el parlamentario (o el independiente en pacto con partidos) que produjo la vacante. Es decir, la Constitución entrega al partido político la total facultad para designar al reemplazante, sin consideración de la opinión de la ciudadanía. Más aún, los parlamentarios elegidos como independientes, fuera de todo pacto, no serán reemplazados en caso de vacancia.

La situación se agrava al considerar la dinámica que se ha generado, atendida la forma de gobierno de nuestro país. En efecto, en el actual sistema presidencialista chileno existe una tajante diferenciación entre Ejecutivo y Legislativo. Los miembros del Congreso no pueden ser al mismo tiempo ministros de Estado, como ocurre en los regímenes parlamentaristas. El problema es que muchas veces los políticos más experimentados de un partido político se encuentran en el Congreso ejerciendo como parlamentarios. Ha existido la tendencia en los últimos años a llamar senadores o diputados para que renuncien a su cargo y poder así ingresar al gabinete de ministros. Ello hace que se vulnere lo que fue la voluntad ciudadana, que votó por una determinada persona, $\mathrm{y}$ no por quien posteriormente designa el partido político. Además, genera una situación de incumbencia para el parlamentario designado, lo que le entrega una clara ventaja electoral para los siguientes comicios. A primera vista, esta facultad entregada a los partidos podría interpretarse como un reforzamiento institucional de ellos, cosa que este Informe debería valorar. Pero, si se piensa mejor, a la larga constituye un factor de debilitamiento de los partidos, pues los desarraiga al permitirles designar mandatarios con total prescindencia de la voluntad de quienes se supone son los mandantes.

Por estas razones, este Informe propone establecer la realización de elecciones complementarias como el único mecanismo de reemplazo de parlamentarios que dejan un escaño vacante, a menos que falte menos de un año para la realización de las próximas elecciones, caso en el cual la vacante no sería provista.

De esta forma, no se prohíbe la renuncia de parlamentarios para entrar al gabinete ministerial; sin embargo, se aumenta considerablemente el costo político de tomar aquella determinación, dado que el escaño debe ser concursado nuevamente ante la ciudadanía y puede, eventualmente, llegar a ser perdido por el partido o pacto que toma la decisión. 


\subsubsection{Financiamiento de las campañas electorales, Leyes 19.884 y 19.885, "Ley de Lobby" y conflictos de interés}

Como se verá en la sección 2.3., este Informe propone revisar la legislación de partidos en el sentido de otorgar, sujeto al cumplimiento de determinadas condiciones, un subsidio fiscal permanente a los partidos políticos. Sin embargo, se hace necesario decir un par de cosas sobre el financiamiento de las campañas electorales y de los eventuales conflictos de interés que suelen abordarse mediante las denominadas leyes "de Lobby". Estas cuestiones - financiamiento electoral, lobby y conflicto de interés - están en el entorno institucional de la legislación de partidos políticos y, por lo mismo, producen efectos sobre ellos. Se tratan a continuación, empezando por el financiamiento electoral. Sobre este, los redactores de este informe tienen coincidencias y divergencias. Se empieza por las primeras.

\section{Financiamiento privado de las campañas electorales: coincidencias}

Desde el año 2003 existe una ley que regula y formaliza los aportes de privados a las campañas electorales. Para este Informe, la reforma de 2003 constituyó un avance, puesto que permitió, en primer lugar, colocar un marco claro en un terreno donde antes primaba la completa opacidad, así como establecer límites al gasto electoral que hasta entonces parecía escalar sin tope. Se puede discutir si ese marco o esos límites, o la regulación específica de ambos, son suficientes, pero nadie puede negar el avance logrado en términos de formalización

En segundo lugar, para este Informe la reforma de 2003 constituyó también un avance en tanto adoptó un modelo de financiamiento mixto de las campañas (es decir, combinando fuentes públicas y fuentes privadas), acorde con lo que ocurre en las democracias modernas, como bien destaca Katz en su trabajo para este Informe. Como se sabe, la ley creó, por un lado, un sistema de financiamiento de cargo fiscal para las campañas electorales, otorgando así un piso mínimo de igualdad para que las distintas opciones políticas puedan dar a conocer sus postulados y candidaturas, lo que es complementado por una franja gratuita de televisión abierta. Y por el otro lado, la ley reguló las vías que puede tomar el financiamiento privado a la política. De esta manera, la reforma reconoció el valor de los aportes privados, como una manera válida 
y legítima de expresar opinión y de participar en política. De ahí que el propósito de fomentar las donaciones ciudadanas, como recoge el trabajo de Salvador Valdés en este Informe, sea una propuesta que hace el Informe.

Con todo, el avance que se hizo en 2003 requiere hoy un nuevo impulso mediante nuevos pasos. Uno urgente de dar es perfeccionar sustantivamente la fiscalización que se hace de los límites máximos de gasto y las rendiciones que efectúan los partidos y candidatos. Por eso, este Informe propone garantizar los recursos que el Servicio Electoral (Servel) necesita para cumplir bien las distintas tareas que la ley le asigna. La estructura legal del Servel, adquirida recientemente, parece tener un diseño adecuado para esas tareas, por lo que ya es hora de dotarlo de los recursos humanos y financieros necesarios para hacerlas con eficiencia y corrección. Estas tareas deben incluir exhaustivas auditorías y análisis de datos y rendiciones, y sobre todo, fiscalizaciones aleatorias en terreno, de manera de contrastar las rendiciones con la realidad de la campaña en la calle.

Otra propuesta en este sentido dice relación con la oportunidad de la rendición de cuentas. Hoy, el artículo 41 de la Ley 19.884 impone que la rendición se realice dentro de los treinta días posteriores a la fecha de la elección. Aquella obligación es correcta, en el entendido que es la información completa de la campaña la que debe ser auditada por el Servel para su veredicto final. Sin embargo, este Informe propone agregar una segunda obligación: que los candidatos y partidos utilicen un software contable uniformado, que sea llenado en línea por los aspirantes desde el primer día y durante todo el proceso de campaña, de manera de ir conociendo en una cuenta única sus ingresos y gastos al momento (aun cuando esta información sea provisional y no auditada), para poder contrastar de mejor manera con lo que ocurre en la calle. Dejar todo para meses después de la votación, como señala Katz en su trabajo para este Informe, puede ser "demasiado tarde". Esta modificación implicaría reformar los artículos 38 y siguientes de la Ley 19.884 respecto de las obligaciones de los administradores electorales y los administradores generales electorales.

También, el Informe propone elevar las sanciones en caso de incumplimiento de las normas sobre financiamiento electoral. En este sentido, propone retomar la idea de que la sanción máxima sea la pérdida del cargo de elección popular (lo que se sumaría a las actuales 
multas que contempla la Ley 19.884 para los casos de exceder el límite de gasto electoral, o de rechazo de cuenta de ingresos y gastos). Para precaver acusaciones frívolas, se propone que esta sanción sea incluida en la Constitución como causal de cesación de cargo, de manera de castigar drásticamente a quien ejerce el cargo público habiendo infringido de manera grave las normas de financiamiento electoral. Para mayor claridad, se debe entender por "grave" el haber infringido la ley por la vía de la comisión de un delito judicialmente acreditado. Asimismo, el Informe propone incluir en la Constitución, como inhabilidad para ser elegido en cargo público, haber recibido una condena penal previa por este tipo de ilícitos ${ }^{7}$.

Asimismo, cabría la manera de pensar el financiamiento privado de las campañas políticas, a la luz de la pregunta por la relación entre partido político y militante candidato. Hoy se pueden hacer aportes a los candidatos, a los partidos o a ambos. Para intentar un aumento de la coherencia interna del partido y de su consistencia programática, podría pensarse en la posibilidad de que un porcentaje de los aportes a los militantes candidatos vaya a sus respectivos partidos. Debería ser un porcentaje bajo, para no interferir demasiado con las preferencias personales de los aportantes y para recompensar a los candidatos diligentes en la recolección de fondos. Pero ese porcentaje sería muy útil para un partido a la hora de diseñar su estrategia de campaña, tanto porque le allega recursos para distribuirlos institucionalmente, cuanto les sirve a las autoridades partidarias para tener información sobre el aporte y gasto electoral de sus militantes candidatos, reduciendo la asimetría de información que existe hoy ${ }^{8}$. La reducción de esta simetría puede servir, además, como una forma de control que redunde en un mejor cumplimiento de las normas sobre financiamiento electoral ${ }^{9}$. Hasta aquí las coincidencias sobre financiamiento privado de las campañas.

${ }^{7}$ Este fue el tenor del mensaje del Ejecutivo en el año 2006, que dio origen a la Ley 20.414, que reformó la Constitución en 2009, pero que en esta parte específica fue finalmente rechazada por el Congreso. Ver en http://www.leychile.cl/Consulta/portada_hl?tipo_norma=XX1\&nro_ley=20414\&anio=2012.

${ }^{8}$ De aprobarse una reforma en este sentido, se debería también aumentar el límite de gasto electoral permitido a los partidos. El límite hoy asciende a un tercio de la suma total de los candidatos del partido (Artículo 5 de la Ley 19.884).

${ }^{9}$ Esta posibilidad de mayor cumplimiento de la legislación fue sugerida por Salvador Valdés en una conversación durante la redacción de este Informe. 
Por último, este Informe propone fomentar una mayor participación de la mujer en las elecciones y equilibrar su posición de candidata. Con el doble propósito de favorecer personalmente a las candidatas mujeres, pero a la vez fomentar que los partidos presenten candidatas de género femenino, este Informe propone establecer un subsidio de campaña diferenciado para el caso de candidatas mujeres, consistente en un $20 \%$ extra del aporte fiscal por voto, el que se repartiría en un $16 \%$ para todas las mujeres que se presenten como candidatas, y $4 \%$ para el partido o pacto patrocinante, pero limitado a los partidos que obtengan candidatas electas (de manera de premiar al partido por conseguir la elección de la candidata y desalentar que coloquen mujeres solo para rellenar listas y obtener un subsidio) ${ }^{10}$.

Financiamiento privado de las campañas electorales: dos divergencias

Como se anunció más arriba, los redactores de este Informe tienen también, a propósito del financiamiento electoral, posiciones divergentes. Estas dicen relación con dos aspectos puntuales: el carácter del aportante y la extensión de la reserva según la magnitud de los aportes. En relación con lo primero, Lucas Sierra sostiene que pueden ser aportantes tanto las personas jurídicas como las naturales, en tanto Francisco Díaz propone que solo puedan serlo las personas naturales y no las jurídicas. En relación con lo segundo, Díaz propone que el mecanismo de la reserva solo puede ser aplicado a aportes pequeños, en tanto Sierra sostiene que a pequeños y grandes. A continuación se exponen sus respectivas razones, empezando por la posición de Francisco Díaz.

Para Díaz, se necesita realizar un drástico cambio en el sistema de aportes privados, tanto para campañas electorales, como para parti-

10 Existe abundante evidencia nacional e internacional en torno a la mayor dificultad de la mujer para acceder a fuentes de financiamiento, muchas de ellas derivadas de la brecha que existe en nuestras sociedades en materia de salarios, acceso al crédito, inserción laboral, acceso a medios de comunicación y, como apunta el PNUD, la existencia informal de "redes solo para hombres" en materia de fuentes financieras (Ver en Empowering Women for Stronger Political Parties. A Guidebook to Promote Women's Political Participation. UNDP and National Democratic Institute for International Affairs (NDI). Leer en: www.undp.org/content/dam/undp/library/gender/gender $\% 20$ and $\% 20$ governance/political\%20Parties\%20Guide\%20Spanish.pdf ). 
dos políticos en época no electoral. Sin cuestionar el régimen general de financiamiento mixto de las campañas, y por el contrario, acogiendo algunas de las propuestas para fomentar la donación de personas naturales que presenta Salvador Valdés en su trabajo para este Informe, se propone una reforma cuyo propósito central sea otorgar el máximo de transparencia posible al sistema de aportes privados a las campañas electorales. Lo que se pretende es un justo equilibrio entre los principios que generalmente informan este tipo de normativas en el mundo, que son el principio libertario, el principio igualitario y el principio de la transparencia.

En primer lugar, se propone restringir la donación a campañas electorales solo a personas naturales. En la actualidad, pueden realizar donaciones a campañas tanto las personas naturales como las personas jurídicas, aunque en este último caso solo pueden hacerlo personas jurídicas con fines de lucro, dejando fuera a las personas jurídicas sin fines de lucro (como corporaciones, fundaciones, sindicatos u otro tipo de organizaciones sociales). En opinión de Díaz, el simple aserto "las empresas no votan" (y por tanto, no deben donar a la política tampoco) tiene completa validez precisamente por su simpleza. Al argumento "las empresas no votan", se suele responder que las empresas tampoco estudian ni hacen deporte ni asisten a eventos culturales, pero, sin embargo, igual les está permitido realizar donaciones a dichas actividades. Esta afirmación no se sostiene. La naturaleza y los efectos públicos de la donación política son muy distintos a la donación en otro tipo de ámbitos. Tan distinto es, que el legislador en el año 2003 hubo de regularla meticulosamente en una legislación particular. La política es especialmente vulnerable ante el riesgo de captura, extorsión, conflicto de interés o tráfico de influencias. A juicio de Díaz, este nivel de cuidado, que la actual ley ya reconoce especial, debe ser ampliado.

En ese sentido, permitir la donación de personas jurídicas abre un espacio muy amplio para la opacidad y para la captura del sistema. Prohibirles a las empresas donar a las campañas no significa que se prohíba la donación privada, simplemente se dice que se haga a través de la vía más adecuada y transparente, que son las personas naturales. Habría que elaborar una teoría muy creativa para justificar que la donación electoral por parte de una empresa forma parte del derecho de expresión de aquel ente jurídico. Además de que existen evidentes problemas prácti- 
cos: más allá de la decisión administrativa de donar ${ }^{11}$, ¿cómo se supone que manifiesta su simpatía política una empresa? ¿Lo hace mediante su directorio? ¿Es representativo este de la opinión política de todos los socios de la empresa? El socio o accionista que no comparte la simpatía política de la empresa a la cual esta va a donar, ¿debe sencillamente acatar las reglas de mayoría interna de la compañía, mayoría que, sabemos, no se rige por el principio de "un hombre, un voto", como en el caso de un partido político, sino que por el tamaño del capital invertido? ¿Debe el minoritario acatar la mayoría interna tal y como si se tratara de una decisión comercial? Por otro lado, ¿qué pasa con los directores que representan a accionistas institucionales, como por ejemplo, un fondo de inversión? O yendo más lejos aún, ¿qué pasa con el trabajador que confía sus fondos a una Administradora de Fondos de Pensiones, la que a su vez es accionista en una empresa que desea donar en favor de un partido o candidato en desmedro de otro?

Entonces, dado que es imposible discernir la simpatía política de la empresa, lo que queda como motivación de la donación es el simple interés de esta por obtener una regulación favorable en alguna determinada materia, aportando, de esa manera, a los candidatos que así se lo aseguren. Suponer que la donación corporativa se dirige a elevar el nivel de la política y la calidad general de las campañas es una ficción que no se sostiene, especialmente cuando se constata la significativa diferencia que existe en los montos que reciben los distintos partidos (como bien muestra el trabajo de Agostini para este Informe). Es decir, lo que prima en el caso de la donación de empresas —más allá del caso de algunos excepcionales benefactores altruistas- es el interés corporativo particular por sobre el interés general. Para estos efectos, se hace prácticamente indiferente la secuencia causal de la donación (es decir, da lo mismo si la empresa dona a un candidato porque él tradicionalmente ha defendido intereses similares a los de la empresa que ahora hace la donación, o por el contrario, si la empresa dona a un candidato para que se sienta comprometido y defienda el interés específico en el futuro), porque el efecto final es el mismo: favorecer al candidato más cercano a sus intereses particulares. ¿Y las personas naturales acaso no

${ }^{11}$ Hoy día la ley habla genéricamente que esa donación requiere "decisión expresa de quienes tengan las facultades de administración, de conformidad con los acuerdos que sobre esta materia haya adoptado previamente el órgano social competente" (artículo 10, inciso $1^{\circ}$, Ley 19.884). 
piensan en su interés particular cuando votan? Efectivamente muchos lo hacen. Pero la diferencia es que cada persona emite un solo voto, el suyo, sin que exista otra prelación que la regla de la mayoría. Cuando se entra al terreno de las donaciones para defender intereses, primará quien realiza la donación mayor. La persona natural que posee riqueza podrá efectivamente donar en mayor cantidad e inclinar la balanza de recursos de campaña para su candidato preferido. Pero, al menos, lo hará transparentemente, conociéndose su origen, nombre, apellido, y además, esa persona tendrá un límite del cual no podrá excederse ni podrá dividirse en numerosas razones sociales. De esa forma, el candidato estará expuesto al escrutinio público respecto de su relación con una persona real y no con un ente ficticio.

Existe una justificación procedimental para la donación de personas jurídicas. Podría pensarse el caso, por ejemplo, de una sociedad de personas en la que todos los socios comparten la misma simpatía política por un determinado partido o candidato, y que ese grupo de personas decida libremente donar a la campaña respectiva. En ese caso, ciertamente no existe una voluntad de la persona jurídica, lo que existe es la voluntad de cada uno de los socios individualmente considerados que están detrás de la compañía. Podría argumentarse que una concreción del derecho a la libre expresión es organizarse y asociarse (la libertad de asociación es también un derecho fundamental) para expresar aquella opinión de manera más eficaz que haciéndolo individualmente. De hecho, de aquí nace la legitimación de la actividad que desarrollan fundaciones, sindicatos y organizaciones de defensa de determinados derechos y causas. De lo que se habla, entonces, es de un tema de efectividad para expresar la opinión, pero no de la esencia del derecho, el que se encuentra plenamente garantizado para la persona natural si esta lo desea ejercer de manera individual. Establecer una limitación a la forma como se expresa la opinión no es algo desconocido. Como se ha dicho, la naturaleza de las campañas políticas hace que amerite un tratamiento especial y, por lo mismo, ya existen varias limitaciones en la legislación. Por ejemplo, está el plazo para desplegar campaña electoral en la vía pública; o los límites de gasto electoral. Ambos limitan la expresión. Siguiendo ese mismo criterio, se justifica prohibir la expresión de simpatía política manifestada en una donación a una campaña hecha a través de una persona jurídica, en aras del principio de transparencia e igualdad que debe informar al sistema de financiamiento. 
Finalmente, se suele argumentar que prohibir el aporte de empresas a la política alentarían las vías ilegales para la donación privada, o como se les llama eufemísticamente, las "vías no convencionales". Un camino es que se realicen financiaciones a través de terceros, en la forma de los Political Action Committees y los 527 groups en Estados Unidos. Como señala Katz en su trabajo para este Informe, existe la tendencia en muchos países a prohibir este tipo de actividades de campaña, sin que se entienda que se esté limitando el derecho de expresión de las personas.

En segundo término, se debiera reforzar el principio de transparencia en los aportes electorales. Se propone establecer solo dos categorías de aporte: el aporte público y el aporte anónimo, eliminando la categoría de aporte reservado que existe en la actualidad. La regla general deben ser los aportes públicos, en los que se individualiza al donante y el monto donado. Excepcionalmente se pueden admitir aportes anónimos, solo para montos pequeños.

En los aportes públicos, se propone mantener una estructura de límites diferenciados según cada puesto en elección, con un tope total, según dispone el artículo 9 de la Ley 19.884. Dado que se propone prohibir la donación de personas jurídicas, estos límites para la donación de personas naturales debieran elevarse. Hoy día los límites son: el equivalente en pesos a 1.000 UF para candidatos a alcalde o concejal; 1.250 UF para parlamentarios; 2.000 UF para candidatos presidenciales en cada vuelta electoral; y 10 mil UF como límite máximo en un mismo proceso electoral considerando a todos los partidos y candidatos que compiten en este. En todos los casos debe existir total transparencia respecto del monto total donado y de la persona del donante.

En el caso de los aportes anónimos, debe permitirse que los ciudadanos puedan donar cantidades pequeñas (inferiores a 20 UF) sin que nadie sepa su identidad ni el monto de la donación, aunque con registro para evitar múltiples donaciones de una persona. Más aún, la idea es facilitar la donación masiva de montos pequeños de parte de los ciudadanos. En este punto, Díaz acoge plenamente lo señalado por Salvador Valdés en su trabajo: implementar un sistema de la donación electrónica a la política vía cajeros automáticos, internet y teléfonos celulares, el que contenga los mecanismos que Valdés señala para reducir el riesgo de extorsión al ciudadano (por ejemplo, a través de la posibilidad 
de revertir la donación en un determinado plazo) ${ }^{12}$. Estas donaciones menores, además, podrían contar con un incentivo fiscal a manera de matching fund, como se propuso para el caso del financiamiento permanente de los partidos políticos. El resto de las donaciones, es decir, las que van desde 20 UF hasta el tope por elección de 10 mil UF, deben ser enteramente públicas.

Por último, en materia de regulación de aportes a los partidos políticos y a sus institutos de formación en períodos no electorales (artículos 21 y 21 bis de la Ley 19.884), Díaz sostiene que debe extenderse también la prohibición de donar a las personas jurídicas. Las cotizaciones regulares que hacen los militantes del partido, inferiores a 20 UF, pueden ser reservadas como información a conocer solo por el partido, sus militantes y el Servicio Electoral (en consonancia con las reglas de publicidad de la militancia). El resto de los aportes a los partidos y sus institutos deben ser públicos.

Por su parte, Lucas Sierra ve también con buenos ojos las Leyes 19.884 y 19.885 de 2003, por intentar formalizar una práctica que hasta ese entonces se desarrollaba en la periferia de la legalidad. Esas leyes establecieron que las personas naturales y las jurídicas pudiesen aportar a las campañas. Y establecieron tres tipos de aportes electorales: anónimos, reservados y públicos. Desde el punto de vista del conocimiento del hecho de un aporte y de su monto, en el caso de los aportes anónimos ambas cosas son sabidas por el aportante y el candidato, el público no sabe. En el caso de los terceros, los aportes "públicos", ambas cosas son sabidas por el aportante, el candidato y, también, el público. En el caso de los segundos, los aportes reservados, el que sabe ambas cosas es el aportante; el candidato y el público no saben ninguna.

En esto los aportes "reservados" se parecen al voto: el votante conoce su preferencia, cosa que ni el candidato ni el público saben. A lo más, saben que entró a la caja secreta en que se vota, pero no cuál fue su voto. Los aportes reservados están concebidos con la misma lógica, pues, como lo demuestra la conquista democrática que significó asegurar el secreto del voto, la total transparencia en materia de preferencias políticas no es necesariamente buena. Esto, pues puede arriesgar la libertad de espíritu con que una persona debe manifestar su preferencia política, tanto a través de un voto, como de un aporte en dinero. Y una

${ }^{12}$ Ver el artículo de Valdés en este Informe. 
cierta reserva en política no solo garantiza la libertad de espíritu para expresar preferencias, sino que, además, dificulta la posibilidad de que exista corrupción y extorsión en las relaciones entre política y dinero. Cuando el voto se hizo secreto, se limitó esta posibilidad.

Según Sierra, entonces, lo que hay que hacer es perfeccionar el mecanismo que existe, mejorando su lógica. ¿Qué significa esto? Significa mantener la autorización para que las personas jurídicas con fines de lucro aporten a las campañas electorales, y mantener los tres tipos de aportes existentes, incluyendo el reservado. Y significa, como lo sugiere Salvador Valdés en su trabajo para este Informe, perfeccionar el mecanismo de los aportes "reservados" por la vía de aumentar el número de potenciales aportantes, permitiendo que las personas jurídicas sin fines de lucro (sindicatos, ONG) puedan también aportar reservadamente.

Asimismo, habría que facilitar el uso por parte de las personas naturales de este mecanismo. Si hoy las personas jurídicas con fines de lucro tienen el incentivo de aportar porque pueden computar tributariamente el aporte como gasto, parece razonable tener un trato equivalente con las personas naturales. Lo ideal sería un beneficio tributario equivalente, pero ante las dificultades prácticas que podría tener su administración fiscal, el trato equivalente podría lograrse mediante un subsidio fiscal al aporte de las personas naturales, una forma de matching-fund. Si esto último no es posible, quizás habría que pensar en equiparar por la vía de eliminar el beneficio tributario que hoy tienen las personas jurídicas con fines de lucro, considerando los aportes a las campañas "neutrales" desde un punto de vista tributario, es decir, no son gasto ni retiro ${ }^{13}$.

Con todo, lo más razonable es maximizar la posibilidad de que los aportantes a una campaña sean los más numerosos que se pueda. La fórmula diseñada para que los aportes reservados sean efectivamente reservados, funciona mejor mientras más aportes distintos concurran. Por esto es necesario incorporar a este esquema a las personas jurídicas sin fines de lucro $\mathrm{y}$, por supuesto, maximizar la participación de personas naturales. Esto último, además, pone un incentivo en los partidos y candidatos para intentar que el público se involucre con la actividad política democrática, posibilitando así una democracia "de base" (grassroots democracy).

${ }^{13}$ De hecho, este tratamiento neutral fue parte de la propuesta original que en materias de financiamiento privado de las campañas hizo la Comisión de Reforma del Estado del CEP en el año 2000. Ver en http://www.cepchile.cl/ dms/lang_1/doc_3521.html, en especial p. 556. 
Se ha sostenido que las personas jurídicas no deben financiar la política porque no votan. Este no parece un argumento muy fuerte, pues las personas jurídicas no desarrollan — no pueden desarrollar - muchas actividades que, sin embargo, pueden financiar (en el campo de la cultura, de la religión, del deporte, etc.). Ante esta objeción suele decirse que los aportes a la política tienen efectos y consecuencias distintos - más graves, supuestamente- que los aportes que se hacen a otras actividades. ¿Es necesariamente así? ¿No podría un aporte a un proyecto cultural, por ejemplo, tener un efecto que, desde algún punto de vista, sea mayor que el aporte a una candidatura? Es difícil responder esto, pues la pregunta es, finalmente, empírica.

Hay, por tanto, buenas razones para permitir la partición de las personas jurídicas. Unas son de principio y otras son prácticas. Entre las primeras, porque el aporte de dinero a una campaña puede ser entendido como una concreción de la libertad de expresión que todas las personas - naturales y jurídicas - tienen. Y, también, porque las personas jurídicas — con o sin fines de lucro- son una concreción del derecho de asociación. Entre las razones prácticas, porque las personas jurídicas con fines de lucro siempre han financiado la política y es probable que lo sigan haciendo en el futuro, por lo que parece prudente facilitarles las vías para que lo hagan sujetándose a reglas establecidas.

Además, como se dijo más arriba, el mecanismo de la reserva para los aportes funciona mejor tanto mientras más aportes se confundan en una candidatura. Eliminar a las personas jurídicas va en contra de este objetivo. Por esto, siguiendo el trabajo de Salvador Valdés, Sierra propone no solo no eliminar las personas jurídicas con fines de lucro, sino abrir también la ley a los aportes de las personas jurídicas sin fines de lucro, además, por supuesto, de todos los aportes de personas naturales que sean posibles.

Hasta aquí la referencia al financiamiento privado de las campañas electorales. Ahora, algunas palabras sobre el lobby y los conflictos de interés.

\section{Lobby, declaraciones de patrimonio y conflictos de interés}

Como último punto, cabe mencionar dos regulaciones que a pesar de no estar directamente vinculadas a la organización misma de los partidos políticos, tienen gran relevancia por cuanto buscan impedir el 
financiamiento irregular de la política. Es evidente que las formas torcidas de financiar la actividad de los políticos y de condicionar eventualmente su actuación pública, pueden tener una perversa influencia en el proceso de toma de decisiones, en el proceso de selección de candidatos, y en definitiva, en la organización y el procedimiento democrático del partido. Para promover partidos políticos de calidad, indispensables para una democracia de calidad, se deben regular los espacios de relación entre el poder económico y el poder político.

En este sentido, se hace necesaria una regulación a las actividades de lobby, en las que exista un claro sistema de registro de los gastos de aquellas empresas y de las reuniones entre autoridades públicas, por una parte, y grupos de interés, directivos y ejecutivos de empresas, y agentes de lobby, por la otra.

Asimismo, se debe perfeccionar el sistema de declaración de intereses y de patrimonio, haciendo más clara la información que se exige en ellas, elevar las sanciones al incumplimiento de elaborar y actualizar dicha información, así como al ocultamiento de información en ellas. Las declaraciones de patrimonio y de intereses, a su vez, deben generar un sistema de inhabilidades a la hora de votar por parte de los oficiales públicos electos, o de participar en una regulación en caso de autoridades de designación política, que se encuentren en dicha situación de conflicto de intereses.

\subsection{REFORMAS ESPECÍFICAS A LA LOC DE PARTIDOS POLÍTICOS}

Como se apuntó en la sección 2.1., la LOC de Partidos Políticos fue dictada en $1987 \mathrm{y}$, en lo fundamental, se mantiene hasta hoy en su forma original ${ }^{14}$. Se trata de una legislación inédita en nuestra historia.

$14 \mathrm{Su}$ texto original está en: http://www.leychile.cl/Navegar?idN orma=29994\&tipoVersion=0. Su texto actual en: http://www.leychile.cl/ Navegar?idNorma=29994. Ha experimentado ocho reformas mediante las siguientes leyes: Ley 18.799, http://www.leychile.cl/Navegar?idNorma=30177\&b uscar=ley+18799, Ley 18.905 http://www.leychile.cl/Navegar?idNorma=30277, Ley 18.963 http://www.leychile.cl/Navegar?idNorma=30331, Ley 19.527 http://www.leychile.cl/Navegar?idNorma=76598\&buscar=ley+19527, Ley $19.806 \mathrm{http} / /$ www.leychile.cl/Navegar?idNorma=198675, Ley $19.884 \mathrm{http} / / /$ www.leychile.cl/Navegar?idNorma=213283, Ley $20.542 \mathrm{http}: / / w w w . l e y-$ chile.cl/Navegar?idNorma=1030935, Ley 20.568 http://www.leychile.cl/ Navegar?idNorma $=1035420$ 
Es la primera que regula a los partidos políticos en cuanto tales, es decir, como organizaciones en sí mismas. Según se ha visto más arriba, hasta el momento en que fue dictada esta ley en 1987, los partidos habían sido solo mencionados por la legislación y nada más que a propósito de los procesos electorales.

La Ley 18.603 tiene una estructura compleja, que intenta cubrir distintas dimensiones de los partidos. Dichas dimensiones se corresponden bien con los siguientes nueve títulos de la ley:

- Título I: De los partidos políticos, de sus actividades propias y de su ámbito de acción

- $\quad$ Título II: De la constitución de los partidos políticos

- $\quad$ Título III: De la afiliación a los partidos políticos

- $\quad$ Título IV: De la organización interna de los partidos políticos

- Título V: Del financiamiento de los partidos políticos

- $\quad$ Título VI: De la fusión de partidos políticos

- $\quad$ Título VII: De la disolución de los partidos políticos

- $\quad$ Título VIII: De las sanciones

- $\quad$ Título IX: De los Tribunales y de las normas de procedimiento ${ }^{15}$

A la luz de los trabajos académicos que contiene este Informe, y a la discusión desplegada en torno a ellos, se propone, principalmente, la revisión de la Ley 18.603 en los seis aspectos que siguen, e incidentalmente, de otras leyes vinculadas a ella, como las Leyes 18.556, LOC sobre Sistemas de Inscripciones Electorales y Servicio Electoral, 19.884 y 19.885, sobre donaciones y financiamiento electoral.

En esta propuesta subyace la convicción de que los partidos políticos son instituciones mixtas, en el sentido de que mezclan funciones de relevancia pública con una entidad de carácter privado. En tal sentido, este Informe considera que la regla de defecto respecto de los partidos es la autonomía asociativa de sus miembros, y el papel de la ley es establecer, excepcionalmente, determinadas exigencias mínimas en atención a la relevancia pública de sus funciones.

${ }^{15}$ Ha habido algunos intentos de modificación de esta ley. El intento más completo fue presentado por el gobierno de Michelle Bachelet en mayo de 2008, que pretendió reemplazarla por un texto nuevo. En julio de 2010, sin embargo, el gobierno asumido ese año retiró el proyecto. Ver el mensaje del proyecto en: http:/camara.cl/pley/pley_detalle.aspx?prmID=6266\&prmBL=5887-06. 


\subsubsection{Carácter jurídico de los partidos, ámbito de competencia y afiliación}

A diferencia de lo que ocurrió bajo la Constitución de 1925, en el corto tiempo que siguió vigente tras su reforma de $1970^{16}$, la Constitución de 1980 no se pronunció sobre el carácter jurídico de los partidos políticos, tratándolos en relación con las personas jurídicas comunes y generales, respecto de las cuales es, en general, aplicable el derecho de asociación. En esto la Constitución y la ley vigente continuaron una tradición antigua en el derecho chileno, en el sentido de que los partidos no son tenidos como personas jurídicas de derecho público. En democracia, esa tradición fue solo interrumpida por un período de tres años, 1970 y 1973, en un período político-institucional muy particular de nuestra historia.

Para este Informe, la discusión sobre el carácter jurídico de los partidos no es urgente en sí misma. Puede ser importante a propósito de la propuesta que se formula más adelante en el sentido de entregar financiamiento público a los partidos bajo ciertas condiciones. La lógica aquí podría ser: si se les está entregando financiamiento público, que su estatuto jurídico sea de derecho público. Este Informe comparte con esta lógica su preocupación por asegurar de la mejor manera el correcto uso de los recursos fiscales, pero sostiene que la respuesta a ello no es necesariamente convertir a los partidos en entes jurídicos de derecho público.

El hecho de darles a los partidos un carácter de derecho público arriesga el peligro de acercarlos demasiado al Estado y alejarlos de la sociedad civil (cuestión que es alertada por el profesor Richard Katz en su trabajo), con la posibilidad, además, de disminuir el carácter de libre asociación que los partidos tienen, lo que es valioso también. Por tanto, este Informe propone no innovar en el carácter jurídico actual de los partidos, poniendo, en cambio, un énfasis especial en un buen mecanismo de control sobre ellos, especialmente en el contexto de financiamiento fiscal que se propone más abajo.

Ahora bien, en relación con su ámbito de competencia, este Informe sugiere que, a nivel constitucional, se defina de una manera más amigable a la forma en que está definido hoy, en que la Constitución parte por decir lo que los partidos "no" pueden hacer. Podría decir, ade-

\footnotetext{
${ }^{16}$ Ver sección 2.1. de este libro.
} 
más, que tienen un papel preponderante en la participación ciudadana, aunque no exclusivo. Asimismo, también en el nivel constitucional, se debiera eliminar la incompatibilidad entre cargos directivos de partidos políticos y de organizaciones gremiales.

A nivel legislativo, además, el Informe propone incorporar dos nuevas facultades. Una, es la de crear o participar en corporaciones y fundaciones, centros de estudio $\mathrm{u}$ otras asociaciones voluntarias, cuyo objeto sea compatible con las actividades permitidas a los partidos. La otra es la facultad de fundar y mantener medios de comunicación.

Por último, el Informe propone que la ley exija que los estatutos de los partidos contemplen en materias de afiliación un procedimiento de dos etapas, a fin de que la negativa a una solicitud por el órgano del partido que la recibió pueda ser revisada por otro órgano del partido. En todo caso, la negativa debe ser pública y fundada.

\subsubsection{Constitución y disolución de los partidos}

Para constituir un partido la ley exige un número inicial de cien firmas para iniciar el trámite de constitución. Con este número inicial se puede registrar un partido como "en formación". Luego, el partido en formación tiene un plazo de doscientos días para reunir las firmas de, al menos, el 0,5\% del electorado que participó en la última elección parlamentaria en cada una de las regiones en que se constituye (durante este plazo se puede deducir oposición por cualquier otro partido inscrito o en formación, Arts. 10 y 11). El mínimo de regiones exigido para constituirse es tres, siempre y cuando sean contiguas. Si no lo son, el mínimo es de ocho regiones (Arts. 5, 6 y 7 de la LOC 19.803).

Este Informe sostiene que la ley debe facilitar la constitución de partidos, pero debe, al mismo tiempo, procurar que estos sean capaces de una visión lo más global posible de los problemas del país, a fin de que puedan cumplir bien la tarea de integración y síntesis que, en general, se espera de los partidos políticos. Como sabemos, los partidos están muy involucrados en el proceso legislativo, y la ley debe ser, en lo posible, común y general. Por lo mismo, los partidos políticos, tan involucrados en el proceso legislativo, deben ser también capaces de articular visiones generales del país, sus problemas y desafíos.

La ley vigente no colabora con ninguno de estos dos principios, por dos razones. Primero, porque el $0,5 \%$ de los votos emitidos en la úl- 
tima elección de diputados es un porcentaje relativamente alto. Piénsese que en la elección de diputados de 1973, la última hecha bajo el imperio de la legislación antes de la actual LOC 18.603, votaron 3.684.990 personas. Esa ley exigía diez mil firmas para constituir un partido. Este número de firmas es el $0,27 \%$ de esa cantidad de votante, no el $0,5 \%$. ¿Qué razones hay para exigir hoy una proporción que es el doble?

La segunda razón por la cual la ley vigente no colabora, tiene que ver con el segundo principio, el que sugiere que los partidos deben poder construir visiones comunes y generales de las necesidades del país. Esto, pues para la constitución de los partidos, la ley establece un privilegio geográfico: si las regiones son contiguas, se necesita reunir el mínimo de firmas en solo tres y no en las ocho que se necesitan en caso de regiones no contiguas. La ley, en otras palabras, tiene un sesgo regionalista. Esto arriesga el peligro de que el proceso legislativo pierda la visión común y general que debe, en principio, tener la ley. Además, este Informe propone más abajo un cierto financiamiento fiscal permanente de los partidos. Estos recursos se obtendrán, vía Ley de Presupuestos, de fondos generales. Una razón adicional para propender a partidos capaces de mirar el país como un conjunto. El regionalismo puede no ser muy funcional a esto.

Este Informe, en consecuencia, propone corregir ambos aspectos por la vía de reducir el porcentaje de firmas exigidas, por una parte, y, por la otra, de aumentar la neutralidad geográfica en la regulación de los partidos. Lo primero, reduciendo desde el $0,5 \%$ hasta un $0,3 \%$. Lo segundo, estableciendo que este porcentaje más reducido se exija en cinco regiones (no en las ocho actuales), sin importar el hecho de que sean contiguas o no. Asimismo, el Informe propone que por el solo hecho de constituirse de esta forma, el partido político pueda funcionar nacionalmente, sin distinguir en qué región consiguió las firmas.

En otro orden de cosas, el Informe propone derogar la disposición actual de la ley que establece la disolución de los partidos en caso de que no alcancen el $5 \%$ de los sufragios válidamente emitidos en una elección de diputados, en cada una de a lo menos ocho regiones, o en cada una de a lo menos tres regiones contiguas, en su caso. La práctica en Chile ha enseñado que los partidos que no alcanzan tal umbral cesan legalmente, pero solo para ser reinscritos con prontitud bajo un nombre análogo. La sanción electoral reflejada en el hecho de no alcanzar representación parlamentaria ya parece ser suficientemente grave para un partido. 
Y si se decide que, no obstante lo anterior, hay que vincular más intensamente los partidos y la representación parlamentaria, contemplando la falta de esta como causal de disolución, el porcentaje no debe ser más alto que el que exija para constituir un partido. Así se reduce la posibilidad de reinscripción con otro nombre.

\subsubsection{Orden interno de los partidos políticos}

En algún sentido, el orden interno de los partidos políticos replica el orden básico de una democracia moderna: hay órganos que dictan reglas (un legislador), otros que administran al amparo de dichas reglas (un gobierno) y otros que sancionan su incumplimiento (jueces). En la ley vigente subyace un esquema parecido. Dispone que los partidos deben tener, al menos, los siguientes órganos (artículo 23): una Directiva Central (gobierno), un Consejo General y Consejos Regionales (legislador) y un Tribunal Supremo (judicial).

\section{Gobierno}

$\mathrm{Al}$ igual que con los poderes del Estado, la ley replica a propósito de los partidos las dos típicas formas en que el gobierno se organiza en una república: presidencialismo y parlamentarismo. La ley permite que los partidos organicen su gobierno interno de una $\mathrm{u}$ otra forma. Como dice el inciso segundo del artículo 24, la Directiva Central de los partidos puede ser elegida por los afiliados o por el Consejo General. La primera alternativa es más presidencialista, la segunda más parlamentaria. Un ejemplo de lo primero podría ser la Democracia Cristiana (donde presidente y mesa directiva se eligen por voto directo); uno de lo segundo, el Partido Socialista (donde presidente y mesa directiva son elegidos por el Comité Central).

Este Informe sostiene que es positivo que la ley sea neutral, como lo es, respecto de la forma de gobierno que adopten los partidos. Es importante que exista un cierto espacio de flexibilidad para que los partidos se organicen de la manera que mejor les parezca, respetando sus tradiciones y su memoria institucional. Lo importante es que sea cual sea la forma que el partido adopte, los militantes en minoría tengan ciertos derechos y que las autoridades sean siempre desafiables en sus cargos. 
En tal sentido, el Informe propone que la ley exija que los estatutos de los partidos contemplen sesiones ordinarias y extraordinarias para el Consejo General y, en general, para los órganos colegiados, deliberativos y resolutivos, al interior de los partidos ${ }^{17}$.

Para que la minoría esté protegida, las sesiones extraordinarias de estos órganos deberían poder ser convocadas por un porcentaje relativamente bajo de votos. Un ejemplo de convocatoria por número reducido de votos lo da la Ley 18.046 sobre Sociedades Anónimas, que exige un mínimo del $10 \%$ de las acciones de una sociedad para convocar a junta extraordinaria. Casi sobra decir que, en principio, los Consejos Generales deben tener responsabilidades y poderes relevantes frente a las directivas de los partidos. Probablemente, una forma parlamentaria de gobierno hace más fácil, institucionalmente hablando, un mayor poder relativo de los Consejos Generales, dado que en cualquier momento el Consejo puede revocar el mandato de la mesa directiva (la que como en todo régimen parlamentario tiene solo plazo máximo de mandato, no período fijo).

Por su parte, la estructura regionalizada de gobierno que la ley prevé para el orden interno de los partidos es, también, susceptible de mejora. La estructura contemplada en la actual LOC ha sido criticada por centralista, ya que los órganos regionales no están consagrados en ella con suficiente fortaleza. En cierta forma, la ley contempla los Consejos Regionales, pero no les asigna facultades específicas. Este Informe propone reforzar la competencia de las directivas y consejos regionales por la vía, por ejemplo, de aumentar su poder a la hora de seleccionar los candidatos a cargos parlamentarios, de alcaldes y concejales.

Donde el centralismo se ve con mayor intensidad es en la jurisdicción interna de los partidos, puesto que solo exige que exista un Tribunal Supremo, sin exigir otros tribunales dispersos geográficamente. Este Informe propone que la ley exija, además, tribunales regionales. A continuación, otras propuestas sobre la jurisdicción en los partidos.

\section{Tribunal Supremo}

Según la ley vigente, los partidos deben tener un tribunal cuyos miembros sean electos por la asamblea general. Su ámbito de compe-

${ }^{17}$ Consejo General o el nombre que la asamblea de carácter nacional tome en cada partido. Por ejemplo, "Comité Central" en los Partidos Socialista y Comunista, o "Junta Nacional" en la Democracia Cristiana. 
tencia está definido en el artículo 28. La ley parece demasiado escueta sobre este órgano fundamental de orden interno. En la práctica, su relativo silencio a la hora de definir estos tribunales ha significado que los procedimientos para comparecer ante ellos no estén adecuadamente formalizados y que no siempre cumplan estándares básicos de debido proceso.

Este Informe propone que la ley formalice con mayor intensidad la dimensión jurisdiccional del orden interno de los partidos. Debe establecer que los partidos se otorguen normas procesales básicas que cumplan ciertas condiciones destinadas a garantizar el debido proceso. Entre ellas: doble instancia (tribunales regionales y un tribunal central de segunda instancia), y para los procedimientos sancionatorios, debe haber, como mínimo, exigencias de emplazamiento debido, bilateralidad de la audiencia, etapa probatoria y apreciación de la prueba, y obligación de fundar las resoluciones.

Como se apuntó más arriba, el Informe propone, además, la creación de tribunales regionales al interior de los partidos. Estos deberían conocer en primera instancia los casos generados en sus respectivos ámbitos de competencia.

\section{Órdenes de partido}

La legislación actual es contraria a las órdenes de votación por parte de los partidos. El artículo 32 las prohíbe expresamente respecto de los parlamentarios a la hora de votar una ley. La ley también prohíbe realizar "recomendaciones" a los senadores llamados a votar como "jurado" (en conciencia). Además, el artículo 21 prohíbe a los partidos dar órdenes al Presidente de la República, ministros de Estado, subsecretarios, embajadores, intendentes, gobernadores, alcaldes, miembros de los Consejos Regionales de Desarrollo y de los Consejos de Desarrollo Comunal, y a los funcionarios de los servicios públicos que sean de la exclusiva confianza del Presidente de la República.

Este Informe proponer revisar esta prohibición tan amplia. No es prudente autorizar las órdenes de partido al Presidente de la República ni a los miembros de la administración pública. En aquellos casos debe primar la responsabilidad política de los militantes que ocupan aquellos cargos y no se debe interferir, por tanto, en el normal desempeño de la administración pública, ni mucho menos, coartar la autoridad presidencial. 
A juicio de este Informe, sin embargo, se justifica plenamente la capacidad de los partidos de dar órdenes a sus parlamentarios. Ellos pertenecen a un cuerpo colegiado de entera generación política. Una disposición en este sentido puede servir, además, como mecanismo de afianzamiento institucional de los partidos.

Para crear un mecanismo de órdenes y disciplina partidaria, se propone establecer al menos tres condiciones: (i) que no se refieran a cuestiones en que los parlamentarios son llamados a votar en conciencia (el caso de los senadores cuando resuelven acusaciones constitucionales); (ii) que la orden se refiera a materias que pueden ser fácilmente reconducidas a los principios que el partido públicamente adhiere; y (iii) que la decisión de la mesa pueda ser sometida a una moción de censura por la asamblea general, la que como se señaló anteriormente, podría autoconvocarse de manera más expedita.

\section{Transparencia}

Las formas a la que se debe someter la conducta de los órganos de los partidos también requieren una revisión. Como bien describe el trabajo de Juan Pablo Luna y Fernando Rosenblatt en este volumen, existe un cierto consenso en el sentido entre los propios dirigentes partidarios en cuanto que esas formas son relativamente opacas y poco estandarizadas, lo que aumenta innecesariamente la asimetría de información entre el partido y el público y, también, entre las directivas de los partidos y su base de militantes.

Para reducir la relativa opacidad en que operan los partidos políticos, el Informe propone exigir a los partidos que tengan a disposición del público información fácilmente comprensible y actualizada sobre:

(i) El número actualizado de sus afiliados

(ii) Estatutos

(iii) Estructura orgánica y competencias de todos los órganos que integran dicha estructura

(iv) Monto de las cotizaciones ordinarias y extraordinarias de sus afiliados

(v) Monto de las donaciones que reciban

(vi) Monto y rendición detallada del subsidio público permanente que reciban (se explica más adelante) 
(vii) Balance anual

(viii) Organizaciones o entidades con las que el partido tenga relaciones y la razón de estas relaciones

(ix) Donaciones públicas que haya recibido el partido y donaciones hechas por este

Esta información debe estar desagregada, orgánica y regionalmente. Más adelante se explican las obligaciones de transparencia respecto de los fondos de campaña.

Se ha sostenido, además, que las formas a la que se somete la conducta de los partidos no garantizan suficientemente una democracia interna $\mathrm{y}$, por tanto, no se garantizan suficientemente los derechos de los afiliados ni el carácter desafiable de los órganos partidarios. Las medidas recién propuestas, con el objeto de reducir la opacidad, ayudan a mejorar el carácter democrático del orden interno de los partidos. Otra medida complementaria es reforzar la exigencia del voto directo de los afiliados para las decisiones relevantes del partido (por lo general, nominación de candidatos y elección de autoridades nacionales), voto que debe ser libre, secreto, informado e igualitario, es decir, debe respetar el criterio de "una persona, un voto". Y en este sentido, también, se propone incorporar como causal de disolución de los partidos la no renovación mediante el voto de los órganos del partido en la oportunidad $\mathrm{y}$ forma que dispongan sus estatutos.

Un punto especialmente delicado es el padrón de militantes. La existencia de uno que esté siempre actualizado y disponible para todos los militantes es condición necesaria para que el partido opere como una organización democrática. Por lo mismo, este Informe propone que la ley apunte a este objetivo de una manera más decidida y explícita que la que tiene hoy. Para esto, la ley debe exigir que un padrón fidedigno y actualizado se encuentre a disposición de cualquier militante en el partido. Y que una copia de él sea mantenida por el Servicio Electoral a disposición de cualquier militante, también.

Sobre la pregunta por la publicidad total del padrón de un partido, este Informe propone que la ley sea neutral, dejando el asunto a la regulación de los estatutos. Pero lo que sí deben hacer todos los partidos, con independencia de la decisión que tomen sobre la publicidad total de su padrón interno, es que este debe ser "público" al menos para sus militantes mediante dos copias fidedignas y permanentemente actualizadas, una en el propio partido y otra en el Servicio Electoral. 


\subsubsection{Mejoras regulatorias}

Hoy el escenario regulatorio de los partidos políticos está conformado por el Servicio Electoral y por un esquema de justicia electoral compuesto por el Tribunal Calificador de Elecciones y Tribunales Electorales Regionales (Artículos 95 y siguientes de la Constitución). Dos leyes orgánicas constitucionales se refieren a estas materias: LOC 18.460 sobre Tribunal Calificador de Elecciones (1985) y LOC 18.556 sobre Inscripciones Electorales y Servicio Electoral (1986). Y una ley ordinaria: la Ley 18.593 que regula los Tribunales Electorales Regionales (1987).

A partir de una reforma introducida en el año 2012, el Servicio Electoral es un órgano doble. Por una parte está el director, que tiene la dirección administrativa, y, por la otra, el Consejo Directivo, que tiene su dirección "superior". Es un modelo interesante, porque puede garantizar cierta independencia política del gobierno de turno, algo fundamental para un regulador de partidos políticos. ¿Por qué? Porque el director no es nombrado por la Presidencia de la República, sino por el Consejo Directivo mediante el sistema de Alta Dirección Pública. Dicho Consejo, a su vez, está conformado por cinco miembros designados por la Presidencia, pero con el acuerdo previo del Senado, adoptado por un quórum alto: $3 / 5$ de sus miembros en ejercicio. Además, la remoción del director está sujeta a la revisión del Tribunal Calificador de Elecciones.

Para el Informe, este es un esquema básico perfectamente plausible y parece una estructura funcional a las mejoras que aquí se proponen. Lo que es necesario hoy es asegurar que los recursos que la institución reciba del Fisco sean suficientes. El Servicio Electoral desarrolla varias tareas, algunas relativamente complejas, como, por ejemplo, la mantención fidedigna y actualizada de un padrón de inscripción automática, o la administración del aporte que hacen los privados a las campañas electorales y del Estado, y la fiscalización de los usos y topes que establece la ley. Y dentro de la propuesta que hace este Informe, además, al Servicio Electoral se le entregaría una nueva tarea: administrar subsidios al funcionamiento permanente de los partidos, tarea que debe ser responsabilidad de su Consejo Directivo. 
Este Informe propone, en consecuencia, mantener y consolidar la recientemente aprobada estructura regulatoria, pero realizar una fuerte inversión en recursos materiales, humanos y financieros, con el objeto de que opere con competencia y corrección.

\subsubsection{Selección de candidatos y elecciones primarias}

Una de las principales funciones de un partido es la selección de personas a ocupar cargos de elección popular. Hoy la legislación dispone lo que sigue:

- $\quad$ El candidato a la Presidencia de la República es seleccionado por el Consejo General del partido (artículo 26, inciso segundo, LOC 18.603).

- Los candidatos a diputados y senadores son seleccionados por el Consejo General a proposición de los Consejos Regionales (artículo 31, LOC).

- La ley nada dice sobre los candidatos a alcaldes y concejales (en rigor, la LOC 18.603 es anterior a la reforma que en 1992 experimentó la LOC de Municipalidades, que introdujo la elección democrática de las autoridades comunales).

- $\quad$ El Consejo General es el llamado a aprobar el ingreso o el retiro del partido de un pacto electoral (Artículo 26, inciso segundo, y Artículo 31, LOC).

Es decir, la actual ley estima que la definición de los candidatos es una tarea propia y esencial de la estructura interna del partido político, en línea con lo señalado en el artículo 2 de la LOC 18.603. Sin embargo, en los últimos años se ha popularizado la idea de descentralizar y transparentar aquella decisión a través de elecciones primarias. Según este mecanismo, ya no es el partido en su estructura interna el que selecciona de manera soberana qué candidatos presentar para los cargos de elección popular (sea a través de designaciones al interior del Consejo General o de los Consejos Regionales, o algún otro órgano interno de decisión, como la Mesa Directiva o la Comisión Política, o incluso, a través de elecciones internas para los militantes del partido en la respectiva comuna, distrito o circunscripción). La idea que comienza a primar es la de elecciones abiertas a toda la ciudadanía inscrita en el territorio 
respectivo, con la sola excepción de militantes de otros partidos, o lo que se denomina: "primarias abiertas". Como bien describe Richard Katz en su trabajo para este Informe, se gesta una creciente demanda en las bases de los partidos y en la sociedad para ya no solo participar en las elecciones como "electorado" (escogiendo entre los candidatos predefinidos por los partidos), sino que como "selectorado" (es decir, participando en el proceso de selección de los candidatos).

De esta forma, a partir de 1993 los partidos políticos en Chile han ido organizando este tipo de procesos eleccionarios. Y a pesar de las complejidades logísticas que un proceso de esta naturaleza conlleva - hasta ahora han debido realizarse con independencia de la ley y con recursos propios-, estos procesos se ha ido extendiendo con el tiempo.

Ha habido cuatro experiencias de elecciones primarias presidenciales en Chile. La primera fue una primaria "semiabierta" en 1993; la segunda fue una primaria abierta en 1999; la tercera fue una primaria abierta en 2005 (pero que no alcanzó a realizarse por deserción de una de las candidatas); y la cuarta fue una primaria abierta, pero regionalizada, en $2009^{18}$.

A nivel parlamentario no ha habido procesos de primarias, salvo elecciones internas donde participó solo la militancia del distrito en el

18 La primera elección primaria presidencial de 1993 tuvo carácter "semiabierta", puesto que podían votar solo los militantes de los partidos de la Concertación, más los independientes que se inscribieran con anterioridad en un registro especial. Compitieron Eduardo Frei Ruiz-Tagle (DC) y Ricardo Lagos Escobar (PPD). Participaron alrededor de seiscientos mil personas, resultando electo como candidato Frei Ruiz-Tagle. La segunda primaria presidencial de 1999 fue abierta a los militantes de los partidos de la Concertación e independientes. Participaron más de un millón quinientos mil personas, imponiéndose Ricardo Lagos Escobar (PPD) por sobre Andrés Zaldívar (DC). La tercera primaria presidencial se realizaría en 2005, entre las precandidatas Michelle Bachelet (PS) y Soledad Alvear (DC), pero Alvear renunció anticipadamente a su precandidatura, siendo proclamada como candidata única de la Concertación Michelle Bachelet. La cuarta elección primaria presidencial se realizó en 2009, entre los precandidatos Eduardo Frei Ruiz-Tagle (DC) y José Antonio Gómez (PR). La novedad fue que la votación se realizaba de manera escalonada en las distintas regiones del país, con una especial norma de salida: si uno de los candidatos acumulaba una distancia superior a $20 \%$ respecto del otro, se suspendía el proceso y se le declaraba ganador. Eso fue lo que ocurrió en la primera de las elecciones regionales efectuada en O'Higgins y Maule: habiendo votado 62 mil personas, el precandidato Gómez obtuvo solo el 36\% de los votos, suspendiéndose el proceso para las demás regiones y proclamándose a Frei Ruiz-Tagle como candidato único de la Concertación. 
caso de algunos partidos (PS y DC). A nivel municipal, existe el precedente de la primaria abierta que realizó en 2008 el partido Renovación Nacional para elegir a su candidato a alcalde en la comuna de Lo Barnechea, y luego, las primarias que realizó la Concertación en 2012, para elegir los candidatos únicos a alcalde en 141 comunas $^{19}$.

\section{Reforma constitucional de 2010}

Como se ha visto, los procesos de elecciones primarias que se han realizado en Chile hasta ahora son procesos informales, organizados sin ningún tipo de apoyo público (más allá de la facilitación de escuelas para que sirvan como recintos de votación). El costo de estos procesos ha sido asumido íntegramente por los partidos y no son menores: se trata de movilizar a decenas o cientos de miles de personas como votantes, con todo el aparataje de sistemas de comunicación y transmisión oficial de datos, urnas, votos, útiles y efectos electorales, sumado a un contingente de varios miles de militantes que actúan como vocales de mesa, apoderados y encargados de recinto, entre otras funciones logísticas.

En el año 1998, se intentó regular legalmente las primarias para determinar los candidatos a la Presidencia de la República. El proyecto de ley presentado por diputados de gobierno regulaba los procedimientos para la preparación, realización, escrutinio y calificación de dichas elecciones ${ }^{20}$. Sin embargo, un grupo de diputados de oposición presentó un requerimiento al Tribunal Constitucional objetando la constitucionalidad de la regulación. El Tribunal acogió el requerimiento (STC rol $279,06.10 .1998)$, sosteniendo que las elecciones primarias que el proyecto en cuestión intentaba regular debían ser consideradas un tipo de votación popular, y por tanto, requería de una reforma constitucional. Hubo posteriormente tres proyectos distintos de primarias, pero ninguno logró avanzar en su tramitación legislativa.

En diciembre del año 2006, el gobierno de la época presentó un proyecto de reforma constitucional que regulaba, entre otras materias, el

${ }^{19}$ En dicho proceso votaron 313 mil personas en todo el país. Este proceso fue antecedido por elecciones primarias abiertas para elegir a sus propios candidatos municipales en el PS y en la DC, en diciembre de 2011 y enero de 2012, respectivamente.

${ }^{20}$ Boletín 2194-06. 
tema de las primarias ${ }^{21}$. El proyecto proponía modificar el inciso 5, del número 15, del Artículo 19 de la Constitución, de manera de añadir dentro de la regulación que la Constitución hace de los partidos políticos, la posibilidad de estos para efectuar elecciones primarias vinculantes, para lo cual se debería dictar una ley orgánica constitucional, y de esa forma, salvar el punto señalado por el Tribunal Constitucional en 1998.

La discusión parlamentaria de dicha reforma tomó cuatro años ${ }^{22}$. En el transcurso de ella, los parlamentarios hicieron los siguientes puntos $^{23}$ :

(i) Que se reafirmara constitucionalmente el principio de que las primarias debían ser voluntarias y no obligatorias para los partidos.

(ii) Que se estatuyera expresamente en la Constitución la prohibición de ser candidato al mismo cargo en la elección general para quienes fueran derrotados en la elección primaria (inicialmente, el mensaje no contenía dicha precisión).

(iii) Que se dejara constancia en la historia fidedigna de la reforma constitucional que la ley orgánica constitucional que regulara las primarias consideraría financiamiento público para dichos comicios.

De esa forma, en enero de 2010 se terminó promulgando la Ley 20.414 que reforma la Constitución, entre otros, el inciso 5 del número 15 del Artículo 19, que señala:

(...) Una ley orgánica constitucional establecerá un sistema de elecciones primarias que podrá ser utilizado por dichos partidos para la nominación de candidatos a cargos de elección popular, cuyos resultados serán vinculantes para estas colectividades, salvo las excepciones que establezca dicha ley. Aquellos que no resulten elegidos en las elecciones primarias no podrán ser candidatos, en esa elección, al respectivo $\operatorname{cargo}(\ldots)$

${ }^{21}$ Texto completo de la reforma en: http://www.leychile.cl/Navegar?idN orma $=1009826 \&$ buscar $=20414$.

22 Esta reforma se incluía dentro de un paquete mayor de reformas en diversas disposiciones de la Constitución, en lo que se denominaba "Reformas para la transparencia, modernización del Estado y calidad de la política". Muchas de las otras reformas incluidas en ese paquete finalmente no prosperaron.

${ }^{23}$ La historia de la Ley 20.414 puede consultarse en: http://www.leychile.cl/Consulta/portada_hl?anio $=2010$ 
Como se puede apreciar, se trata de un sistema voluntario (la reforma habla del sistema que “...podrá ser utilizado...”); de resultados vinculantes para los partidos que participen de él (aunque se abre espacio para excepciones establecidas en la ley); y que prohíbe a los candidatos derrotados a participar como candidatos al mismo cargo en esa misma elección general ${ }^{24}$.

\section{Proyecto de ley para regular las elecciones primarias}

En septiembre de 2011, el gobierno presentó un proyecto de ley que establece el sistema de elecciones primarias para la nominación de candidatos a Presidente de la República, parlamentarios y alcaldes. Este proyecto fue aprobado por la Cámara de Diputados en enero de 2012, encontrándose a esta fecha en discusión de segundo trámite ante el Senado $^{25}$.

El proyecto en términos generales aplica los principios establecidos en el inciso 5, del número 15, del Artículo 19 de la Constitución (después de la reforma introducida por la Ley 20.414), y crea un sistema de primarias que puede ser utilizado por los partidos o pactos de partidos para todos los cargos de elección popular que existen en Chile (presidente, senadores, diputados, alcaldes y concejales). La ley obviamente respeta el principio expresado en la Constitución en cuanto que este sea un procedimiento voluntario para los partidos políticos ${ }^{26}$.

Además de ello, la ley contempla que las elecciones son organizadas por el Servicio Electoral, con cargo al Fisco. Asimismo, el proyecto contempla financiamiento público para las campañas electorales de los candidatos — aunque excluye el acceso a la franja gratuita de televisión.

\section{¿Fortalecen a los partidos políticos las elecciones primarias?}

Estatuir elecciones primarias para seleccionar a los candidatos a los cargos de representación popular significa alterar el método tradi-

${ }^{24}$ Debe entenderse que esta prohibición rige incluso para los candidatos independientes que participaron en la primaria, según precisó el Ministro SEGPRES José Antonio Viera-Gallo durante la tramitación del proyecto.

${ }^{25}$ Boletín 7911-06.

${ }^{26}$ En abril de 2012, la senadora Soledad Alvear (DC) presentó un proyecto de reforma constitucional que proponía que las elecciones primarias fuesen obligatorias para todos los partidos o pactos, y que se efectuaran simultáneamente. 
cional que han utilizado los partidos políticos. Este método tradicional - esto es, nominación a través de un órgano interno - ha significado que los partidos mantengan una importante cuota de poder. Introducir las primarias abiertas en este proceso acarrea un importante cambio organizacional y cultural que se debe sopesar en su justa dimensión, por cuanto se incorporan nuevas variables y actores - como la participación de ciudadanos que no necesariamente militan en el partido- en el proceso de selección.

La literatura señala ventajas y desventajas de los procedimientos de primarias abiertas (también llamadas "generales"). Richard Katz resume muy bien la discusión en el trabajo que hace para este Informe ${ }^{27}$. Por una parte, existe la justificación normativa de las primarias como método que fomenta la participación, que descentraliza las decisiones acercándolas a los ciudadanos, y que aumenta la transparencia. Ya no se seleccionan los candidatos "entre cuatro paredes", sino que es la ciudadanía la que los elige. Además, las primarias tendrían la virtud de abrir opciones para que los retadores puedan desafiar a las autoridades establecidas.

Por otro lado, hay voces críticas a las primarias. En primer lugar, se discute si estas generan o no una ventaja electoral a quienes las utilizan como método (lo que se denomina "el bono primaria", es decir, que el hecho de haber sido elegido a través de una primaria haría al candidato más atractivo ante la ciudadanía). La evidencia es relativamente concluyente en cuanto que las primarias no generan ese "bono" para el candidato ganador, aunque se admite que, en ciertos casos, la primaria ayuda a posicionar el nombre de un candidato hasta entonces menos conocido. Además, se admite que son una herramienta privilegiada para zanjar diferencias intrapartidarias o intracoalición, las que, de otra manera, no habría cómo zanjar. En relación con la mecánica de selección, la literatura tiende a advertir que las primarias escogen candidatos subóptimos, por cuanto en ellas se tiende a escoger al candidato más cercano al votante medio partidario y no al candidato más cercano

27 Un buen recuento de literatura internacional y latinoamericana se puede encontrar también en Carey (2008) "El bono de la primaria en América latina", en Arturo Fontaine et al., Reforma de los partidos políticos en Chile, Santiago: PNUD/ CEP, CIEPLAN, Libertad y Desarrollo, y Proyectamérica. Disponible en las páginas web de ambos centros de estudio: http://www.cepchile.cl/dms/lang_1/doc_4391.html así como en http://www.cieplan.org/media/ publicaciones/archivos/176/Capitulo_6_P3.pdf 
al votante medio general. En términos de la institución partidaria, como bien apunta Katz, la excesiva descentralización de la decisión sobre los candidatos termina restando consistencia programática a los partidos. Incluso, este mecanismo puede ser fácilmente utilizado por la propia directiva central (que cuenta con mayores recursos de poder que la base) para contrarrestar fuerzas internas contrarias.

En resumen, para parte importante de la literatura, lo que provoca las primarias es una desintegración vertical del partido, restándole efectividad y coherencia interna a la organización. Ello es caldo de cultivo para que el partido sea asediado por empresarios individuales de la política, los temidos caudillos, quienes tienen los recursos para movilizar (y “acarrear") a los ciudadanos para votar en estos eventos internos.

Finalmente, las elecciones primarias chocan con otros principios y propósitos que se puede desear fomentar en los partidos, como es una participación política más equilibrada entre hombres y mujeres. Como señala Richard Katz en su trabajo para este Informe, la colisión se produce por cuanto “(...) las exigencias de las cuotas se determinan según una norma basada en el outcome, mientras que las primarias se determinan con una norma basada en el input". De esta forma, ambos tipos de reformas (primarias y acción afirmativa) buscan aumentar la democracia y la representatividad dentro de los partidos políticos, pero lo hacen de manera diferente y potencialmente conflictiva. Así, terminan enfrentándose los seguidores de la igualdad de género con los seguidores de la descentralización y la democratización interna ${ }^{28}$.

¿Cómo favorecer los aspectos positivos de las primarias (participación y transparencia) y evitar los efectos negativos (caudillismo y debilitamiento de la coherencia interna)?

${ }^{28}$ En el caso chileno, la posición de la mujer en una elección primaria abierta para cargos de baja magnitud distrital (por ejemplo, de mantenerse el sistema binominal parlamentario, o para el caso de las alcaldías, que son uninominales) seguiría siendo una posición de relativa inferioridad. Es ilustrativo analizar la única experiencia que ha habido en Chile al respecto, como fueron las elecciones primarias que realizó la Concertación en abril de 2012 para elegir a sus candidatos a alcalde en 141 comunas de todo el país (elección en la que votaron más de 313 mil personas). Los partidos llevaron como candidatas a 55 mujeres en un universo de 336 candidatos (es decir, solo el 16,3\% de todos los candidatos fueron mujeres). Lograron ser electas 21 mujeres, lo que corresponde al $14,8 \%$ de los candidatos elegidos vía primaria. 
En opinión de este Informe, la solución pasa por una adecuada regulación que, por una parte, garantice participación en condiciones ecuánimes y que, por otra, guarde la facultad de los partidos para decidir finalmente las formas y los casos de realización de estos eventos.

En concreto, parece apropiado que las primarias sean concebidas como mecanismo voluntario y no obligatorio para los partidos; que estas cuenten con una regulación que garantice los principios del debido proceso electoral, y que la organización sea supervisada por el Servicio Electoral. En definitiva, a mayor el número de votantes, mayor será la deliberación real de la ciudadanía, acercando la naturaleza de estos procesos a lo que es una elección real, como ocurre en Estados Unidos a propósito de la elección presidencial, o como ocurrió en Chile en la primaria de 1999, o como comienza a ocurrir en algunos países de Europa en estos momentos, que comienzan a introducir el mecanismo. Mientras mayor el número de votantes, menor será la incidencia de los recursos propios de los candidatos y de las prácticas nocivas que afectan a la coherencia de los partidos, como es el acarreo de electores y el clientelismo.

Esas condiciones generalmente se darán en elecciones que implican grandes "selectorados", como es el caso de una elección presidencial. En otros países puede pensarse también en la elección de gobernadores (en el caso de estados federales), o en Chile, la elección de senadores donde la elección abarca a varias decenas de miles de "selectores" en la circunscripción.

¿Pero qué pasa en el caso de elecciones de cargos de electorado menor, como concejalías, alcaldías o diputaciones? Los efectos perversos de esta norma pueden presentarse en toda su magnitud. ¿Se podría prohibir la primaria para aquellos casos? Es difícil hacerlo, porque, en definitiva, es voluntad del partido realizarlas. Pero distinto es alentarlas, aceptarlas a todo evento, y peor aún, estigmatizar a quienes prefieren no hacer este proceso motejándolos como partidos antidemocráticos.

Una norma que podría estudiarse al respecto es una cláusula de participación para que el torneo electoral primario sea vinculante. La actual redacción de la Constitución permite excepciones, señalando el inciso 5, del número 15 del Artículo 19:

(...) cuyos resultados serán vinculantes para estas colectividades, salvo las excepciones que establezca dicha ley (...) 
Es decir, este Informe propone que se entregue al partido o al pacto de partidos la facultad de, al momento de convocar a la elección primaria y determine los candidatos, establecer un porcentaje mínimo de participación electoral para que la elección primaria sea efectivamente vinculante.

Junto a ello, este Informe sugiere que los partidos o pactos de partidos que vayan a primarias para cargos que no sean de Presidente de la República, tengan la facultad de escoger el padrón electoral que decidirá la consulta. De esa forma, puede decidirse que para la selección de cargos municipales voten solo los militantes del partido o pacto de partidos que van a la elección.

Finalmente, el Informe propone introducir este cambio gradualmente por la vía de ofrecer financiamiento fiscal solo para las campañas de primarias en que se defina la candidatura a la Presidencia de la República. Obviamente, esto no implica prohibir las otras primarias. Estas quedan autorizadas, pero sin financiamiento fiscal para sus campañas. Una alternativa así, gradual, podría reducir el riesgo de los efectos adversos que las primarias pueden generar para la institucionalidad de los partidos y, al mismo tiempo, permitiría ir aprendiendo de la experiencia.

\subsubsection{Financiamiento permanente no electoral de los partidos políticos}

Las vías no electorales de financiamiento de los partidos son varias: las cotizaciones ordinarias o extraordinarias de sus afiliados, las donaciones, las asignaciones testamentarias que se hagan en su favor y los frutos y productos de los bienes de su patrimonio. Estos ingresos, ordena la ley, deben tener un origen nacional (Artículo 33).

Como se analizó más arriba, los partidos también participan del mecanismo de financiamiento que, desde 2003, opera para las elecciones. En este sentido, los partidos, así como los candidatos, pueden ser beneficiarios de los aportes que los particulares hagan a las campañas. Asimismo, en este esquema, los gastos electorales en que incurran los partidos reciben un subsidio fiscal (Artículos 13 y siguientes de la Ley 18.884).

No hay en Chile, sin embargo, un subsidio fiscal permanente para los partidos políticos. Este Informe propone establecer ese tipo de financiamiento. Como se ha sostenido más arriba, los partidos son indispensables para el buen funcionamiento del sistema democrático y para 
el buen gobierno de la sociedad. Por esto, del trabajo de los partidos en democracia se derivan bienes públicos de una relevancia difícil de exagerar, por lo que está plenamente justificado su financiamiento público.

El subsidio fiscal permanente o complementario al electoral, que este Informe propone, no consiste en un subsidio a todo evento. Está sujeto, en cambio, a un conjunto de condiciones o, si se quiere, a "contraprestaciones" por parte de los partidos subsidiados. Se estima necesario evitar el subsidio a todo evento a fin de reducir el riesgo de que los partidos se transformen en organizaciones parasitarias de fondos públicos, fondos públicos que, por lo demás, determinarán los propios partidos a través de sus miembros con representación parlamentaria.

Por el contrario, lo que se pretende es que el subsidio fiscal opere como incentivo, como un acicate, para que los partidos desarrollen activamente las tareas que una sociedad democrática espera de ellos. Es decir, el subsidio es entendido siempre como un complemento a la actividad y esfuerzo de los propios partidos. Las condiciones o prestaciones subsidiables $\operatorname{son}^{29}$ :

a) Subsidio a las cuotas de los militantes

b) Subsidio a las donaciones de los ciudadanos

c) Subsidio a talleres de debate y diálogo político

d) Subsidio para la preparación de candidatos a los cargos de elección popular

e) Subsidio a la formación de militantes

f) Subsidio a la mejora del conocimiento para la actividad política, como, por ejemplo, los asesores legislativos y asesores para la oposición

${ }^{29}$ En este punto, el Informe sigue de cerca los trabajos que Salvador Valdés ha desarrollado sobre esta materia durante los últimos años. Estos son: Subsidio a la participación en partidos políticos, Puntos de Referencia $\mathrm{N}^{\circ} 317$, Centro de Estudios Públicos, enero 2010, http://www.cepchile.cl/dms/lang_1/ doc_4530.html; Financiamiento político para profundizar la democracia, Puntos de Referencia No 294, Centro de Estudios Públicos, agosto 2008, http:// www.cepchile.cl/dms/lang_1/doc_4150.html; "Financiamiento público de partidos políticos: propuesta para Chile", en Reforma de los Partidos Políticos en Chile, Fontaine, Larroulet, Navarrete y Walker (eds.) (Santiago: PNUD, CEP, CIEPLAN, Proyectamérica, Libertad y Desarrollo), 2008, pp. 297-337, en la web de ambos centros de estudios: http://www.cepchile.cl/dms/lang_1/ doc_4385.htmlpp y http://www.cieplan.org/media/publicaciones/archivos/176/ Capitulo_6_P3.pdf 
Los subsidios señalados en las letras a) y b) anteriores suponen una aplicación más mecánica. Los de las letras siguientes, en cambio, suponen una aplicación más discrecional. El carácter colegiado del Consejo Directivo del Servicio Electoral favorece una adecuada implementación de este tipo de subsidios.

Adicionalmente, para los subsidios a), c), d) y e), este Informe propone distinguir entre mujeres y hombres, entregando un porcentaje adicional en el caso de las militantes y candidatas mujeres, de manera de fomentar la participación femenina en los partidos, y su efectiva capacitación. La utilización de los subsidios de las letras c), d) y e) deberá ser debidamente acreditada por el partido político ante el Servicio Electoral a través de la contratación pública de los talleres y cursos de formación y capacitación en materias relacionadas, y de registros de realización y asistencia a los respectivos eventos.

La cantidad porcentual de estos subsidios debería quedar, en lo posible, establecidas mediante fórmulas en la legislación de partidos, para orientar su asignación anual por la Ley de Presupuestos. Esto ayudaría a evitar que se abriera toda la discusión año a año en la Ley de Presupuestos, y fueran los partidos con representación parlamentaria los que se asignaran a sí mismos, al fragor de la contingencia, financiamiento fiscal. Esto, como escribió Barros, arriesga el peligro de "erosionar la confianza política"30, en línea con la teoría que el propio Richard Katz ha elaborado internacionalmente y que consigna en este Informe: el riesgo del "partido cartel", que termina llegando a acuerdos con los partidos de la competencia para controlar la oferta y entregarse beneficios mutuamente en las diversas instancias de gobierno y del parlamento.

${ }^{30}$ Op. cit., ver nota 1 de este capítulo. 